\title{
Calf and dam characteristics and calf transport age affect immunoglobulin titers and hematological parameters of veal calves
}

\author{
F. Marcato, ${ }^{1,2 *}$ H. van den Brand, ${ }^{1} \odot$ B. Kemp, ${ }^{1} \odot$ B. Engel, ${ }^{3} \odot$ S. K. Schnabel, ${ }^{3} \odot$ C. A. Jansen, ${ }^{4}$ \\ V. P. M. G. Rutten, ${ }^{5,6}$ A. P. Koets, ${ }^{7,8} \odot$ F. A. Hoorweg, ${ }^{2}$ G. de Vries-Reilingh, ${ }^{1}$ A. Wulansari, ${ }^{1}$ \\ M. Wolthuis-Fillerup, ${ }^{2}{ }^{\circ}$ and K. van Reenen ${ }^{2}$ (C) \\ ${ }^{1}$ Adaptation Physiology Group, Wageningen University \& Research, PO Box 338, $6700 \mathrm{AH}$ Wageningen, the Netherlands \\ ${ }^{2}$ Wageningen Livestock Research, Wageningen University \& Research, PO Box 338, 6700 AH Wageningen, the Netherlands \\ ${ }^{3}$ Biometris, Wageningen University \& Research, PO Box 16, 6700 AA Wageningen, the Netherlands \\ ${ }^{4}$ Cell Biology and Immunology Group, Wageningen University \& Research, PO Box 338, 6700 AH Wageningen, the Netherlands \\ ${ }^{5}$ Department of Infectious Diseases and Immunology, Faculty of Veterinary Medicine, Utrecht University, PO Box 80165, 3508 TD Utrecht, \\ the Netherlands \\ ${ }^{6}$ Department of Veterinary Tropical Diseases, Faculty of Veterinary Science, University of Pretoria, P/Bag X04, Onderstepoort 0110 , \\ Republic of South Africa \\ ${ }^{7}$ Wageningen Bioveterinary Research, Wageningen University \& Research, PO Box 65, 8200 AB Lelystad, the Netherlands \\ ${ }^{8}$ Department of Population Health Sciences, Faculty of Veterinary Medicine, Utrecht University, PO Box 80163, 3508 TD Utrecht, the Netherlands
}

\section{ABSTRACT}

This study aimed to investigate effects of transport age of calves (14 vs. $28 \mathrm{~d}$ ), and of calf and dam characteristics, on immunoglobulin titers and hematological variables of veal calves. Calves $(\mathrm{n}=683)$ were transported to a veal farm at 14 or $28 \mathrm{~d}$ of age. Natural antibodies N-IgG, N-IgM, and N-IgA against phosphorylcholine conjugated to bovine serum albumin (PC-BSA) were measured in serum of the dams 1 wk before calving and in first colostrum. These antibodies were also measured in serum of calves $1 \mathrm{wk}$ after birth, $1 \mathrm{~d}$ before transport, and in wk 2 and 10 posttransport at the veal farm. Hematological variables were assessed in calves 1 $\mathrm{d}$ before transport and in wk 2 posttransport. One day before transport, titers of N-IgG, N-IgM, N-IgA, and neutrophil counts were higher, and lymphocyte counts were lower in 14-d-old calves compared with 28-d-old calves. In wk 2 at the veal farm, calves transported at $14 \mathrm{~d}$ of age had higher N-IgG titers and neutrophil counts, but lower N-IgM and N-IgA titers, and lymphocyte counts than calves transported at $28 \mathrm{~d}$. In wk 1 and $1 \mathrm{~d}$ before transport, $\mathrm{N}$-Ig in calves were positively related to N-Ig in colostrum. In wk 2 and 10 at the veal farm, N-IgG in calves was positively related to N-IgG in colostrum. The N-IgG titers in calves at the dairy farm were negatively related to the likelihood of being individually treated with antibiotics or other medicines at the veal farm. Our results suggest that calves transported to the veal farm at $28 \mathrm{~d}$ of age showed a more advanced development of their adaptive immunity than

Received April 21, 2021.

Accepted October 1, 2021.

*Corresponding author: francesca.marcato@wur.nl calves transported at $14 \mathrm{~d}$ of age. Quality of colostrum might have long-term consequences for N-IgG titers and immunity in veal calves.

Key words: veal calf, transport age, immunoglobulin, hematology, robustness

\section{INTRODUCTION}

In the Netherlands, male (and surplus female) calves born on dairy farms are transported at a minimum age of $14 \mathrm{~d}$, first to a collection center and then to a veal farm (Marcato et al., 2018). Effects of transport on calf physiology and health have been previously documented (e.g., Knowles et al., 1999; Masmeijer et al., 2019; Marcato et al., 2020a,b, 2021). Recent observational studies have found associations between the background and rearing practices at the dairy farm of origin and mortality rate of calves at the veal farm (Winder et al., 2016; Renaud et al., 2018a). Correspondingly, BW and the clinical health condition of calves upon arrival at the veal farm (Renaud et al., 2018b; Scott et al., 2019) as well as biomarkers analyzed in a blood sample taken at arrival, including immunoglobulins (Pardon et al., 2015; Goetz et al., 2021), cholesterol (Renaud et al., 2018b), or specific immune cell counts (von Konigslow et al., 2020), were all significantly correlated with later risks of disease and mortality. Collectively, these studies suggest that both transport and husbandry characteristics at the dairy farm of origin may be important determinants of the biological state of a calf when it arrives at the veal farm. This biological state, in turn, may predispose the animal to disease, poor performance, or premature death during the subsequent rearing period. This process could also be described in terms of robustness of calves. Robustness is defined as the ability of an 
animal to cope with environmental challenges and to bounce back rapidly after challenges occur (Colditz and Hine, 2016). Robustness can be measured, for example, through physiological indicators in the blood or by assessment of the health status or mortality rate, which could be considered the ultimate indicators of animal robustness (Marcato et al., 2018; de Almeida et al., 2019). So far, identifying which specific environmental or animal-based factors may play a causal role in influencing robustness of veal calves has not yet been well investigated.

Transporting a calf from the dairy farm to the veal farm at $14 \mathrm{~d}$ of age might be convenient for dairy farmers because it minimizes the rearing costs of calves on dairy farms. However, at this age, immune components of calves are not completely functional because calves younger than $28 \mathrm{~d}$ are in the so-called "immune gap period" due to the combination of a decreasing passive immunity and the absence of a mature adaptive immune system (Chase et al., 2008). Transporting calves 2 wk later than current practices may allow the adaptive immunity of calves to further develop (Chase et al., 2008), and thus, calves might be more robust upon arrival at the veal farm. Therefore, the first objective of the current study was to investigate the effect of 2 different transport ages (14 vs. 28 d) on potential biomarkers of calf robustness, including natural antibody titers specific for phosphorylcholine conjugated to bovine serum albumin (PC-BSA), and the hematological profile. Phosphorylcholine is an abundant environmental antigen, present on bacterial membranes, fungi, and parasites, and is a useful model for pathogen recognition (Pinkert et al., 1989). In the current study, the combination of PC with BSA allowed also to detect natural autoantibodies, because BSA can be considered as a self-antigen for both cows and calves. Additionally, as reported by Mayasari et al. (2016), natural autoantibodies reflect levels of maternal antibodies after consumption of colostrum; thus, they are an important measure of passive immunity. The current paper will use the term $\mathbf{N}-\mathbf{I g}(\mathbf{N}-\mathbf{I g G}, \mathbf{N}-\mathbf{I g} \mathbf{M}$, and $\mathbf{N}-\mathbf{I g} \mathbf{A})$ to indicate presence of PC-BSA-specific natural antibodies. The second objective of the current study was to investigate effects of calf characteristics (such as birth weight, sex, breed) and cow characteristics [parity, ease of birth, dry period length (DPL), colostrum quality, and milk yield] on these same biomarkers. These calf and cow characteristics might be important for the development and future performance of calves (Godden et al., 2005; Roland et al., 2016). Finally, this study aimed to examine relationships between early biomarkers of calf robustness and individual treatments with antibiotics and other medicines at the veal farm as well as carcass weight at slaughter. The latter are assumed to reflect the capacity of the calves to successfully adapt to the conditions at the veal farm. Therefore, all calves were individually followed prospectively from birth at the dairy farm until the end of the rearing period at the veal farm. Findings from this experiment on clinical health and growth performance of calves are reported in a companion paper (Marcato et al., 2022).

\section{MATERIALS AND METHODS}

\section{Experimental Design}

The experiment was executed between March 2019 and May 2020 and was approved by the Central Committee on Animal Experiments (The Hague, the Netherlands; approval number 2017.D-0029). The experimental design was a matrix consisting of 13 dairy farms and 8 veal farms. The allocation of calves to the respective age groups (labeled as 14 and $28 \mathrm{~d}$, respectively) was done by the researchers during their weekly visits on the dairy farms. The dairy farms included in this experiment were selected in collaboration with the Netherlands Agricultural and Horticultural Association (LTO Nederland). Farmers participated in the experiment on a voluntary basis. For the recruitment, we looked for dedicated farmers, willing to participate, with a dairy farm size large enough to provide enough calves to be included in the experiment on a weekly basis. The various calf rearing and management systems applied on the dairy farms that participated in the current experiment largely covered the variation that is present in the Dutch dairy sector. Calves $(\mathrm{n}=683)$ originated from 13 Dutch dairy farms. Within each farm, calves were allocated to the age treatment group (14 or $28 \mathrm{~d}$ ) based on the week of birth to avoid confounding between the experimental factor age and the effects of dairy farm of origin and veal farm, and to make sure that calves from both age groups and from all dairy farms of origin entered the veal farm at the same moment. Calves born in the first $2 \mathrm{wk}$ from the start of the experiment left the dairy farm at a minimum of $28 \mathrm{~d}$ of age (range in actual age between 28 and $36 \mathrm{~d}$ ), and calves born in the subsequent 2 wk left the dairy farm at a minimum of $14 \mathrm{~d}$ of age (range in actual age between 14 and $22 \mathrm{~d}$ ). Consequently, all calves born at all dairy farms within this 4-wk timeframe were transported to the same veal farm (see Figure 1). For reasons of clarity we decided to use 14 and $28 \mathrm{~d}$ as basic labels for the 2 factor levels. At each transport day, 2 transporters collected calves from the dairy farms (6 and 7 dairy farms, respectively) and brought these directly to the veal farm, meaning that for each veal farm in total 4 transports were performed. The timeframe shown in Figure 1 was repeated 8 times, meaning that calves born in each timeframe were trans- 


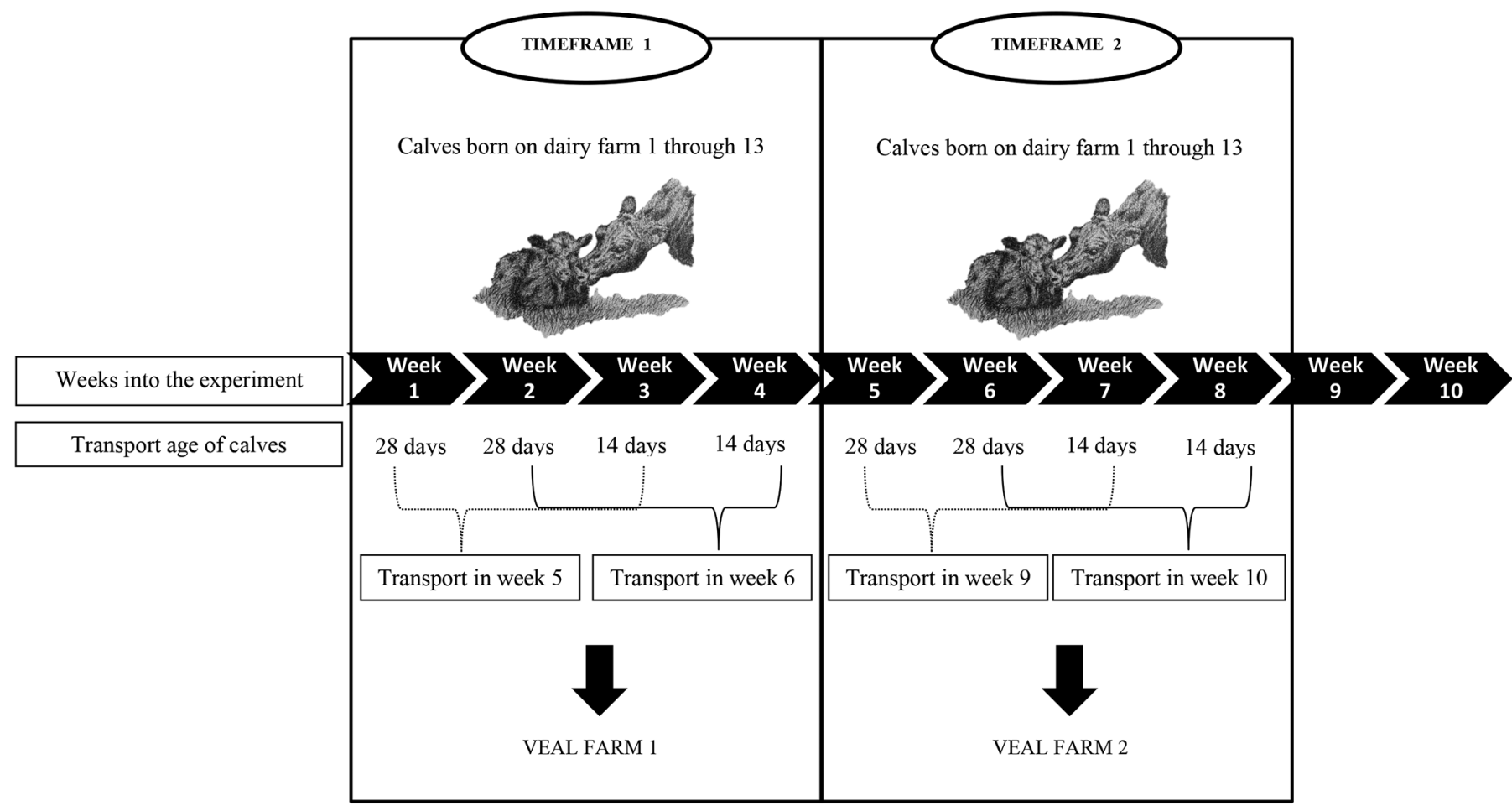

Figure 1. Representation of the experimental design. The timeframe was repeated 8 times until veal farm 8 was completely filled with calves. In total, this took a period of 34 consecutive weeks, which consisted of almost an entire calving season.

ported to a different veal farm. We appreciate the fact that because of this design, inevitably, some events or environmental conditions that might have occurred in the first 2 wk of a time frame might not have occurred in the second $2 \mathrm{wk}$, and that this might have created a difference between calves of different ages independent from the experimental factor age. However, since a total of 13 dairy farm and 8 veal farms took part in the current experiment, resulting in a total of 104 $(13 \times 8)$ independent subgroups of calves in terms of time and place, each consisting of both 14-d-old and 28-d-old animals, the likelihood of a systematic difference between transport age groups due to the fact that the calves of the 28-d treatment group did not share the same environmental conditions as the calves of the 14-d treatment group during the first 2 wk after birth was deemed negligible. The recruitment of calves into the experiment stopped when the last veal farm was filled with calves. At the veal farms (average herd size of 1,065 calves), calves were individually housed on slatted floor in the first 3 wk posttransport, after which they were housed in groups ( 5 or 6 calves per pen) with a space allowance of $1.8 \mathrm{~m}^{2} /$ calf. The veal farms recruited for this experiment were affiliated to the same veal company and used similar diets for their calves (i.e., milk replacer labeled D350, Denkavit B.V., for a 3-phase feeding program, and a 2-phase feeding program for the solid feed consisting of a mixture of concentrates and straw), and they applied an all-in, allout system. Our experimental calves were fully blended in, meaning that calves were completely mixed with the other calves already present at the veal farm and were treated in the same way as the other nonexperimental calves. Veal farmers were blinded to the background and age of calves.

\section{Descriptive Statistics}

A total of 363 calves were allocated to the 14-d treatment group, and 320 calves were allocated to the $28-\mathrm{d}$ treatment group. On average, 85 (range: 70-100) calves were transported to each veal farm. Out of 683 calves, 508 were males and 175 were females. With regard to breed, 246 calves were Belgian Blue $\times$ Holstein Friesian crossbreds, 235 calves were Holstein Friesians, and 202 calves were crossbreds other than Belgian Blue $\times$ Holstein Friesian. With regard to parity, 90 calves were born from first-parity cows, 165 from second-parity cows, 151 from third-parity cows, and 252 from cows with parity higher than 4 . Both calves and cows did not 
receive any preventive medicines, such as vaccines, on source dairy farms. Calves were also not vaccinated at the veal farm operations.

\section{Sample Size Calculation}

The number of experimental units required in the present study was based on a power analysis. In this study, the actual number of calves assigned to each treatment group (>300 animals per transport age group) fully complied with the required number of experimental units calculated based on previous work by Marcato et al. (2020b) and Engel et al. (2016), which took place under experimental and commercial conditions, respectively. The variance used in the power calculations underlying the present study was the residual within-farm variance. For proportions, the "residual" variance was the multiple of the Bernoulli variance and the largest value was obtained for an expected proportion of 0.5. It was assumed that dependence was adequately covered by random main effects for farms, and that fixed effects were largely within farms. Moreover, we focused on the comparison between the levels of the main factor of interest (i.e., age of transport). The minimum difference of interest was specified as a fraction 0.3 of the residual standard deviation, the desired power was 0.90 , and the level of significance for a 2 -sided test was set at 0.05 . These values resulted in a sample size of 235 per age group, 470 in total when a fully balanced design would be assumed. To be able to deal with an unbalanced design, we aimed for a surplus of animals.

\section{Sample Collection}

All pregnant dams at the dairy farms were bled approximately $1 \mathrm{wk}$ before the expected day of calving. A sample $(10 \mathrm{~mL}$, Vacuette, Greiner BioOne) was obtained from the tail vein of cows. Samples $(\mathrm{n}=813)$ were kept at room temperature for a few hours until centrifugation $\left(3,000 \times g\right.$ for $15 \mathrm{~min}$ at $\left.4^{\circ} \mathrm{C}\right)$, then serum was collected by decanting and stored at $-20^{\circ} \mathrm{C}$ until analysis. Colostrum samples $(15 \mathrm{~mL}, \mathrm{n}=490)$ were collected by the dairy farmer as soon as possible after the birth of each calf. Samples were temporarily stored in a freezer $\left(-20^{\circ} \mathrm{C}\right)$ on each dairy farm until they were processed in the laboratory and then they were stored at $-80^{\circ} \mathrm{C}$ until analysis. Calves $(\mathrm{n}=$ 683) were blood sampled 1 wk after birth, $1 \mathrm{~d}$ before transport, and 2 and $10 \mathrm{wk}$ posttransport (at the veal farm). The sampling moment in wk 1 was chosen to get an indication of the amount of antibodies derived from passive immunity in calf serum at an early stage after birth. The sampling moment on the day before transport was selected to check whether the calves still relied on immune protection obtained from their dams or if they already started their endogenous production, and to make a comparison with immunity of calves at later time points, which, according to our expectations, would primarily reflect the endogenous production of antibodies by the calf. Samples $(10 \mathrm{~mL})$ were collected from the jugular vein of calves into serum vacutainer tubes (Vacuette, Greiner BioOne). Samples were kept at room temperature for a few hours until centrifugation $\left(3,000 \times g\right.$ for 15 min at $\left.4^{\circ} \mathrm{C}\right)$, and then serum was decanted and stored at $-20^{\circ} \mathrm{C}$ until analysis.

\section{Measurement of Immunoglobulin Titers in Serum Samples of Cows and Calves, and in Colostrum}

Titers of N-IgG, N-IgM, and N-IgA measured in serum samples of cows, calves, and in colostrum were determined with indirect ELISA according to a method published previously (Mayasari et al., 2016). Prediluted samples (1:10) in PBS mix (PBS $+1 \%$ horse serum $+0.05 \%$ Tween) were added to the plates coated with different amounts of PC-BSA (PC-1011-10, Bioresearch Technologies; Supplemental Table S1, https: //doi.org/10.6084/m9.figshare.16940611). As indicated in Supplemental Table S1, natural antibodies N-IgG and N-IgM were detected using 1:20,000 diluted sheep polyclonal antibovine IgG-heavy chain conjugated to horseradish peroxidase (catalog no. A10-100P, Bethyl Laboratories), and 1:20,000 diluted rabbit polyclonal antibovine IgM conjugated to horseradish peroxidase (catalog no. A10-100P, Bethyl Laboratories). Natural antibody $\mathrm{N}-\mathrm{IgA}$ was detected using 1:10,000 diluted sheep polyclonal antibovine IgA conjugated to horseradish peroxidase (catalog no. A10-131P, Bethyl Laboratories). Serial dilutions of serum and colostral samples to detect $\mathrm{N}-\mathrm{IgG}, \mathrm{N}-\mathrm{IgM}$, and $\mathrm{N}-\mathrm{IgA}$ in serum samples started at 1:40 (4 steps). After the last $1.5 \mathrm{~h}$ of incubation at room temperature with the conjugates, plates were washed with demi-water. Each well of the plate was filled with $100 \mu \mathrm{L}$ of substrate tetra methyl benzine (TMB; Sigma Aldrich Chemie), which contained MilliQ water, $1 \%$ TMB, and $10 \%$ TMB buffer. Plates were then incubated for $30 \mathrm{~min}$ at room temperature. After the incubation, the reaction was stopped by adding $50 \mu \mathrm{L}$ of $\mathrm{H}_{2} \mathrm{SO}_{4}$ solution in each well. Extinctions were measured with a Multiskan reader (Lab Systems) with a wavelength of $450 \mathrm{~nm}$. Titers were calculated based on $\log _{2}$ values of the dilution that gave extinction closest to $50 \%$ of Emax, where Emax represents the highest mean extinction of standard positive serum present on each plate (Ploegaert et al., 2007).

In addition to the measurement of N-Ig titers in colostrum, each dairy farmer assessed the quality of 
the first colostrum of each cow, using a refractometer (model 101 ATC, MS Schippers). Values obtained from the refractometer (Brix values) are indicative of the amount of immunoglobulins, including IgG (Quigley et al., 2013; Bartier et al., 2015).

\section{Measurement of the Hematological Profile of Calves}

Blood samples (5 mL) were collected from the jugular vein of calves into EDTA vacutainer tubes (Vacuette, Greiner BioOne) $1 \mathrm{~d}$ before transport and in wk 2 posttransport. Samples were stored for a few hours at $4^{\circ} \mathrm{C}$; then, Rimondia B.V. (a company specialized in analyzing blood samples of veal calves) analyzed the samples by fluorescence flow cytometry (XT-1800i, Sysmex Europe $\mathrm{GmbH}$ ) for a complete hematological profile, including hemoglobin, hematocrit, red blood cell count (RBC), mean corpuscular hemoglobin (MCH), mean corpuscular volume (MCV), mean corpuscular hemoglobin concentration, red cell distribution width, white blood cell count (WBC), and WBC differentiation (lymphocytes, neutrophils, monocytes, basophils, and eosinophils).

\section{Data on Calf and Cow Characteristics}

Characteristics of both calves and cows were obtained from questionnaires filled in by dairy farmers and collected during the weekly visits on the dairy farms. Calf characteristics included BW at birth, breed, and sex. Body weight at birth was measured on an portable scale (model MW/VHD300/D from Breinler International B.V.). The scale was always calibrated before use. Cow characteristics included parity, DPL, total milk yield during the previous lactation, number of days open before pregnancy, and information on the ease of birth of the calf. Ease of birth was recorded as a binary response: score $=0$ referred to a calving process without the assistance of the farmer, and a score $=1$ indicated assistance of the farmer during the calving process.

\section{Performance Data}

At both dairy and veal farms, individual treatments of calves with antibiotics and other medicines were recorded by the farmer. Information on individual treatments included the following data: (1) whether or not a calf was treated with antibiotics or other medicines (e.g., this latter category referred to products other than antibiotics, such as antiinflammatories, multivitamins, and anticoccidial medications); (2) whether single or repeated antibiotic/medical treatments were applied;
(3) age at which treatments were applied. Finally, hot carcass weights at slaughter were obtained from the slaughterhouse.

\section{Statistical Analyses}

Continuous response variables (e.g., N-IgG, N-IgM, and N-IgA in serum and colostrum samples), were analyzed with a linear mixed model (LMM). Components of variance were estimated with REML, employing procedure MIXED from SAS 9.4 (SAS Institute Inc.). Residuals were always checked for normality and homogeneity of variance and variables were log-transformed when needed. Response variables that were expressed as proportions (e.g., hematocrit), were analyzed with a generalized linear mixed model (GLMM), comprising a logit link function and a multiple of the Bernoulli variance as an "error" variance. Inference was by penalized quasi-likelihood (which is equivalent to the use of pseudo-likelihood), employing SAS procedure GLIMMIX. Approximate F-tests (Kenward and Roger, 1997) were used for fixed effects. Subsequent pairwise comparisons were done with Fisher's least significant difference method. When the fixed part of the model included both quantitative covariates and qualitative factors, interactions between covariates and factors were tested to see whether the assumption of equal slopes was tenable. Individual medical treatments applied were analyzed as a binary response (calf treated or not), also with a GLMM with a logit link and the Bernoulli variance as the "error" variance. Given this background, the following Table 1 shows a more detailed overview about the response variables analyzed in the current study and all specifications about the models. Model 6 included the fixed effect of week (time) and comprised a random effect of calf (see Table 1). For the calf effects, a first-order autoregressive model (based on the actual distance between time points) was adopted to introduce correlation in the model between repeated measurements on the same animal. Two-way interactions between fixed effects were included in all models, and interactions were considered not statistically significant when $P>0.05$.

All the analyses shown in Table 1 were also conducted for a subset of samples, excluding first-parity cows. These models (models 1-8, Table 1) included DPL (d), total milk yield $(\mathrm{kg})$, and number of days open as additional covariates to obtain regression coefficients to test for significant relationships between these factors and the respective response variable.

To test relationships between N-Ig in serum of calves with the ones in serum of the dams and in colostrum, $\mathrm{N}-\mathrm{Ig}$ in colostrum and cow serum samples were added 
Marcato et al.: EFFECTS OF TRANSPORT AGE ON IMMUNITY OF VEAL CALVES

1437

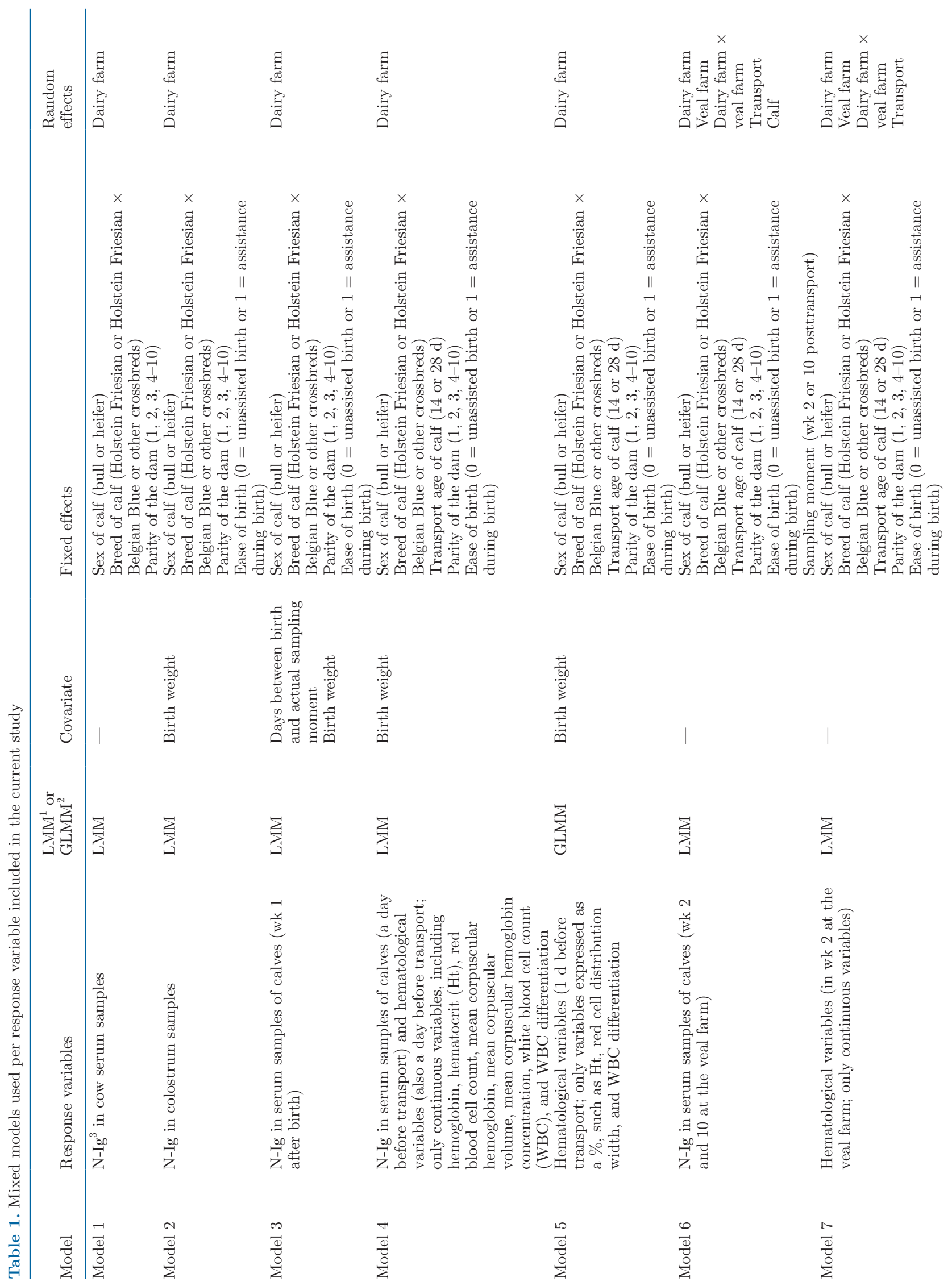

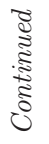


Marcato et al.: EFFECTS OF TRANSPORT AGE ON IMMUNITY OF VEAL CALVES

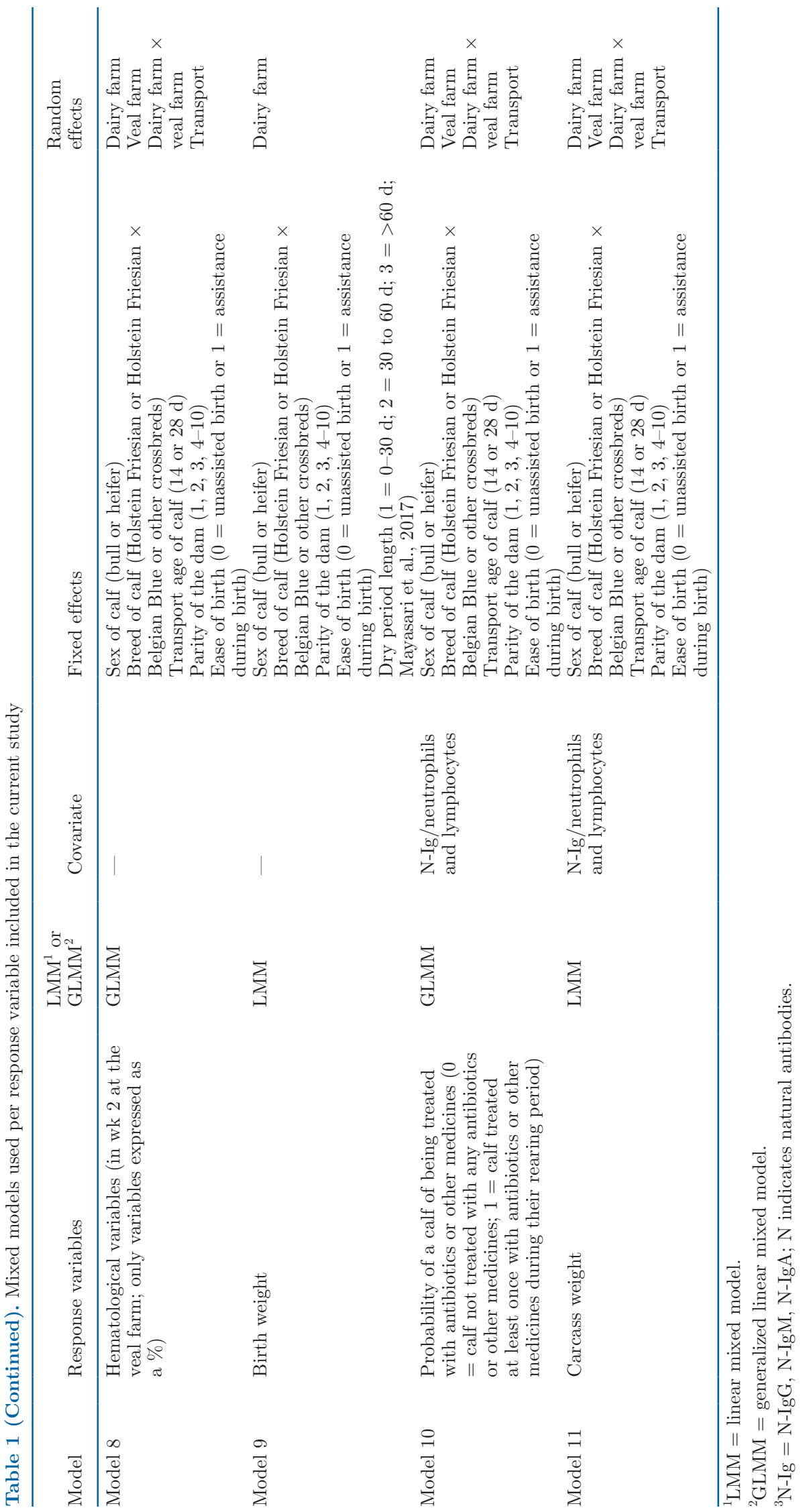


in the model for data analyzed with models 3,4 , and 5 . These analyses were run separately from the original run of the models.

In all analyses, effects with $P \leq 0.05$ were considered statistically significant, whereas those with $0.05<P<$ 0.10 were considered as tendencies toward significance.

\section{RESULTS}

\section{Effects of Transport Age}

Transport age influenced the hematological variables of calves $1 \mathrm{~d}$ before transport and in wk 2 posttransport. One day before transport, calves that were transported at $28 \mathrm{~d}$ had a lower $\operatorname{MCV}(\Delta=-1.67 \mathrm{fL})$, $\mathrm{MCH}(\Delta=-35.6 \mathrm{amol})$, red cell distribution width $(\Delta$ $=-1.12 \%)$, WBC $\left(\Delta=-0.7 \times 10^{9} / \mathrm{L}\right)$, neutrophils [cell count $\left(\Delta=-1.1 \times 10^{9} / \mathrm{L}\right)$ and proportion $(\Delta=$ $-7.97 \%)$ ], and monocytes [cell count $(\Delta=-2.12 \times$ $\left.10^{9} / \mathrm{L}\right)$ and proportion $\left.(\Delta=-2.14 \%)\right]$ compared with calves transported at $14 \mathrm{~d}$ (all $P<0.05$; Table 2). In addition, calves transported at 28-d had higher RBC $\left(\Delta=0.3 \times 10^{12} / \mathrm{L}\right)$, lymphocytes $[$ cell count $(\Delta=0.63$ $\left.\times 10^{9} / \mathrm{L}\right)$ and proportion $\left.(\Delta=8.14 \%)\right]$, basophil count $\left(\Delta=0.02 \times 10^{9} / \mathrm{L}\right)$, and eosinophils [cell count $(\Delta=$ $\left.0.15 \times 10^{9} / \mathrm{L}\right)$ and proportion $\left.(\Delta=1.19 \%)\right]$ compared with calves transported at $14 \mathrm{~d}$ (all $P<0.05$; Table 2).
In wk 2 posttransport, calves transported at $28 \mathrm{~d}$ had a lower $\operatorname{MCV}(\Delta=-1.81 \mathrm{fL}), \operatorname{MCH}(\Delta=-24 \mathrm{amol})$, WBC $\left(\Delta=-1.21 \times 10^{9} / \mathrm{L}\right)$, neutrophils [cell count $(\Delta$ $\left.=-1.61 \times 10^{9} / \mathrm{L}\right)$ and proportion $\left.(\Delta=-12.05 \%)\right]$, and basophil count $\left(\Delta=-0.02 \times 10^{9} / \mathrm{L}\right)$ compared with calves transported at $14 \mathrm{~d}$ (all $P<0.05$; Table 3). Additionally, calves transported at $28 \mathrm{~d}$ had higher mean corpuscular hemoglobin concentration $(\Delta=0.39$ $\mathrm{mmol} / \mathrm{L})$, lymphocytes [both cell count $(\Delta=0.50 \times$ $\left.10^{9} / \mathrm{L}\right)$ and proportion $\left.(\Delta=11.9 \%)\right]$, and proportion of monocytes $\left(\Delta=0.40 \times 10^{9} / \mathrm{L}\right)$ compared with calves transported at $14 \mathrm{~d}(P<0.05$; Table 3$)$.

\section{Interaction Between Time and Transport Age at the Veal Farm}

An interaction between transport age of calves and time relative to transport age was found (Figure 2AB). One day before transport and in wk 2 and 10 at the veal farm, transport age influenced the levels of serum N-Ig of calves (Tables 4 and 5). One day before transport, calves transported at $14 \mathrm{~d}$ had higher N-IgG, N-IgM, and N-IgA titers $(\Delta=0.75, \Delta=0.71$, and $\Delta$ $=0.62$, respectively) compared with calves transported at $28 \mathrm{~d}$ (all $P<0.01 ;$ Table 4$)$.

In wk 2 posttransport, calves that were transported at $14 \mathrm{~d}$ had higher N-IgG titers $(\Delta=0.65)$, but lower

Table 2. Effects of transport age and sex of calves on hematological profile measured in plasma of calves $1 \mathrm{~d}$ before transport to the veal farm at $\mathrm{d} 14$ or 28 of age (LSM \pm SEM)

\begin{tabular}{|c|c|c|c|c|c|c|c|c|}
\hline \multirow[b]{2}{*}{ Parameter $^{1}$} & \multicolumn{2}{|c|}{ Transport age } & \multirow[b]{2}{*}{$\mathrm{SEM}^{2}$} & \multirow[b]{2}{*}{$P$-value } & \multicolumn{2}{|c|}{ Sex } & \multirow[b]{2}{*}{ SEM } & \multirow[b]{2}{*}{$P$-value } \\
\hline & $14 \mathrm{~d}$ & $28 \mathrm{~d}$ & & & Bull & Heifer & & \\
\hline No. of calves & 339 & 316 & & & 490 & 165 & & \\
\hline Hemoglobin, mmol/L & 6.58 & 6.47 & 0.18 & 0.56 & $6.37^{\mathrm{a}}$ & $6.68^{\mathrm{b}}$ & 0.16 & $<0.01$ \\
\hline Hematocrit, \% & 30.94 & 30.51 & 0.78 & 0.55 & $30.10^{\mathrm{a}}$ & $31.34^{\mathrm{b}}$ & 0.72 & $<0.01$ \\
\hline $\mathrm{MCV}, \mathrm{fL}$ & $34.76^{\mathrm{a}}$ & $33.09^{\mathrm{b}}$ & 0.42 & $<0.01$ & 33.84 & 34.01 & 0.40 & 0.56 \\
\hline $\mathrm{MCH}$, amol & $734.1^{\mathrm{a}}$ & $698.5^{\mathrm{b}}$ & 9.6 & $<0.01$ & 711.4 & 721.1 & 8.7 & 0.08 \\
\hline $\mathrm{MCHC}, \mathrm{mmol} / \mathrm{L}$ & 21.20 & 21.14 & 0.11 & 0.68 & 21.09 & 21.25 & 0.10 & 0.09 \\
\hline RDW, SD, \% & $37.85^{\mathrm{a}}$ & $36.73^{\mathrm{b}}$ & 0.20 & $<0.01$ & 37.30 & 37.37 & 0.23 & 0.98 \\
\hline RDW, CV, \% & 31.27 & 32.18 & 0.16 & 0.06 & 31.73 & 31.64 & 0.18 & 0.93 \\
\hline $\mathrm{RBC}, 10^{12} / \mathrm{L}$ & $9.0^{\mathrm{a}}$ & $9.3^{\mathrm{b}}$ & 0.15 & $<0.01$ & $8.9^{\mathrm{a}}$ & $9.3^{\mathrm{b}}$ & 0.15 & 0.01 \\
\hline WBC, $10^{9} / \mathrm{L}$ & $11.4^{\mathrm{a}}$ & $10.7^{\mathrm{b}}$ & 0.37 & 0.01 & 10.9 & 11.1 & 0.38 & 0.59 \\
\hline Neutrophils, $10^{9} / \mathrm{L}$ & $4.68^{\mathrm{a}}$ & $3.58^{\mathrm{b}}$ & 0.13 & $<0.01$ & 4.13 & 4.21 & 0.14 & 0.88 \\
\hline Neutrophils, \% & $40.32^{\mathrm{a}}$ & $32.35^{\mathrm{b}}$ & 0.61 & $<0.01$ & 36.50 & 36.42 & 0.73 & 0.39 \\
\hline Lymphocytes, $10^{9} / \mathrm{L}$ & $4.79^{\mathrm{a}}$ & $5.42^{\mathrm{b}}$ & 0.17 & $<0.01$ & 5.09 & 5.13 & 0.17 & 0.79 \\
\hline Lymphocytes, ${ }^{3} \%$ & 43.28 & 51.42 & 0.60 & & 47.36 & 46.76 & 0.72 & \\
\hline Monocytes, $10^{9} / \mathrm{L}$ & $14.94^{\mathrm{a}}$ & $12.82^{\mathrm{b}}$ & 0.91 & $<0.01$ & 13.39 & 14.37 & 0.92 & 0.12 \\
\hline Monocytes, \% & $15.47^{\mathrm{a}}$ & $13.33^{\mathrm{b}}$ & 0.34 & $<0.01$ & 13.28 & 14.18 & 0.21 & 0.14 \\
\hline Basophils, $10^{9} / \mathrm{L}$ & $0.10^{\mathrm{a}}$ & $0.12^{\mathrm{b}}$ & 0.002 & $<0.01$ & 0.11 & 0.12 & 0.002 & 0.08 \\
\hline Basophils, \% & 0.95 & 1.11 & 0.02 & 0.32 & 1.02 & 1.06 & 0.01 & 0.72 \\
\hline Eosinophils, $10^{9} / \mathrm{L}$ & $0.13^{\mathrm{a}}$ & $0.28^{\mathrm{b}}$ & 0.02 & $<0.01$ & 0.21 & 0.18 & 0.02 & 0.57 \\
\hline Eosinophils, \% & $1.20^{\mathrm{a}}$ & $2.39^{\mathrm{b}}$ & 0.14 & $<0.01$ & $1.84^{\mathrm{a}}$ & $1.59^{\mathrm{b}}$ & 0.14 & $<0.01$ \\
\hline
\end{tabular}

${ }^{\mathrm{a}, \mathrm{b}} \mathrm{LSM}$ within a factor and row lacking a common superscript differ $(P \leq 0.05)$.

${ }^{1} \mathrm{MCV}=$ mean corpuscular volume; $\mathrm{MCH}=$ mean corpuscular hemoglobin; $\mathrm{MCHC}=$ mean corpuscular hemoglobin concentration; RDW = red blood cell width; $\mathrm{RBC}=$ red blood cells; $\mathrm{WBC}=$ white blood cells.

${ }^{2} \mathrm{SEM}=$ pooled standard error.

${ }^{3}$ The statistical model for this variable did not converge. 


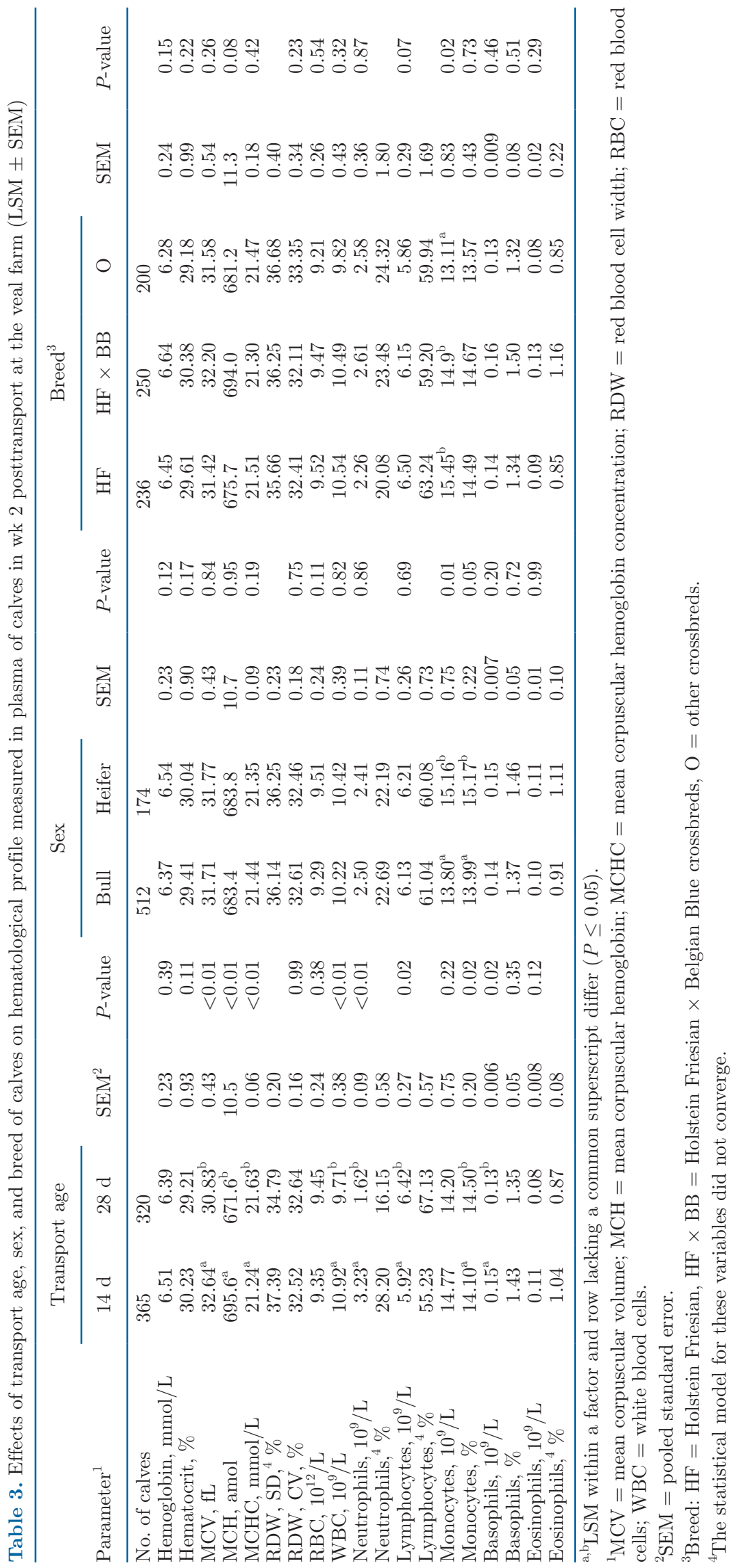




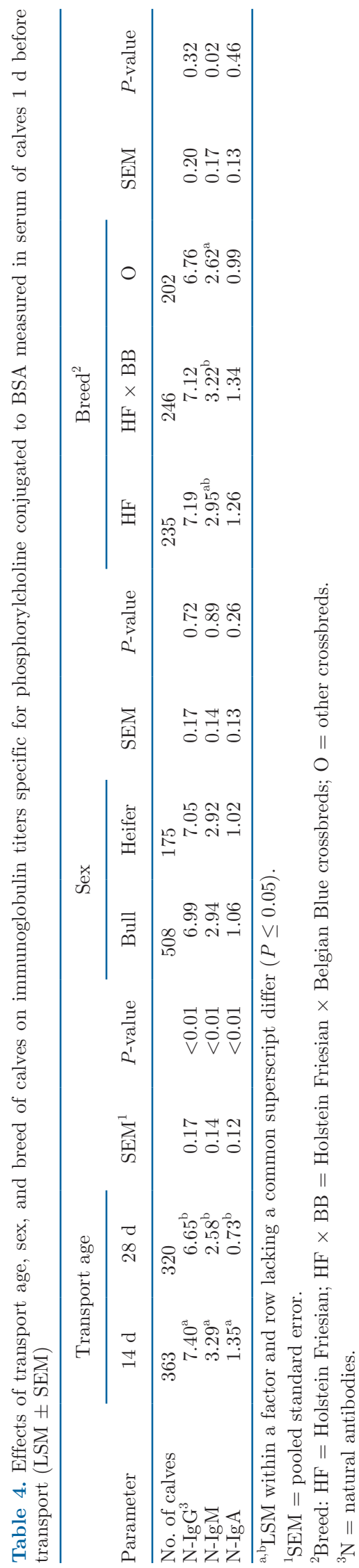

$\mathrm{N}-\operatorname{IgM}(\Delta=-1.19)$ and $\mathrm{N}-\operatorname{IgA}(\Delta=-0.56)$ compared with calves transported at $28 \mathrm{~d}$ (Table 5 ). In wk 10 posttransport, no effect of transport age was found on N-Ig.

\section{Effects of Calves' Sex}

One day before transport, bull calves had lower values of hemoglobin $(\Delta=-0.31 \mathrm{mmol} / \mathrm{L})$, hematocrit $(\Delta=-1.24 \%)$, and $\operatorname{RBC}\left(\Delta=-0.4 \times 10^{12} / \mathrm{L}\right)$ and

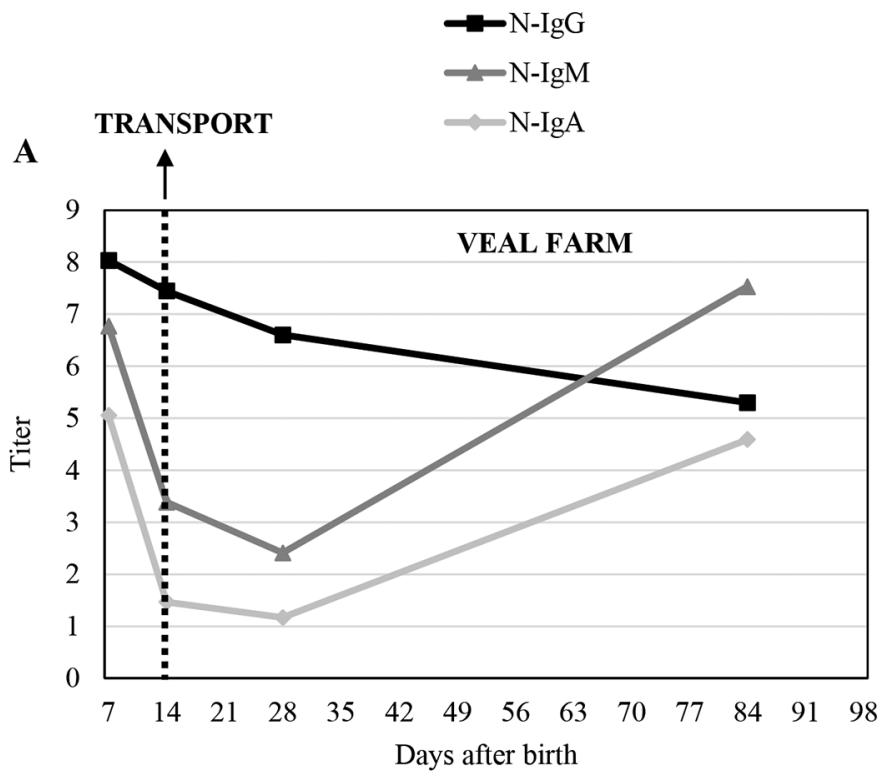

TRANSPORT

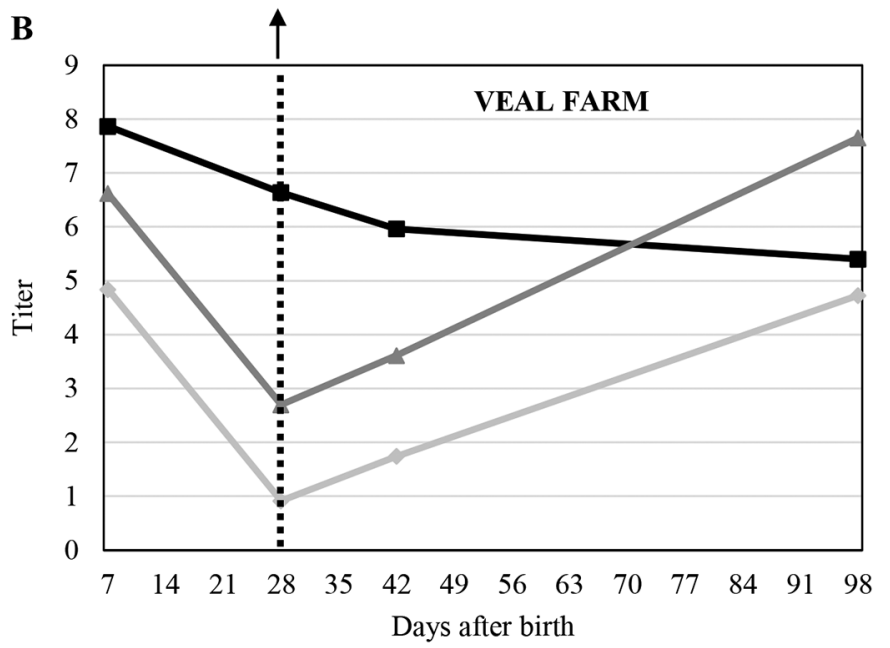

Figure 2. Immunoglobulin titers specific for phosphorylcholine conjugated to BSA (N-Ig) measured in serum of calves $1 \mathrm{wk}$ after birth on dairy farm, $1 \mathrm{~d}$ before transport to the veal farm, and in wk 2 and 10 posttransport. Panel A illustrates the comparison between the 3 immunoglobulin isotypes in calves transported at $14 \mathrm{~d}$ from dairy to veal farms, whereas panel B shows the comparison in calves transported at $28 \mathrm{~d}$ of age. Calves belonging to the 28-d group (B) were 2 wk older than the 14-d group (A). N = natural antibodies. 
more eosinophils $(\Delta=0.25 \%)$ compared with female calves (all $P<0.05$; Table 2 ). In wk 2 posttransport, bull calves had a lower monocyte count $(\Delta=-1.36 \times$ $\left.10^{9} / \mathrm{L}\right)$ and proportion $(\Delta=-1.18 \%$; both $P<0.05$; Table 3) compared with female calves. Bull calves received colostrum with a lower amount of N-IgG titer compared with female calves $(\Delta=-0.35 ; P=0.04)$, whereas sex did not affect the other titers measured in colostrum, or N-IgG, N-IgM, and N-IgA titers measured in serum samples of cows and calves (Table 4, 6, 7, 8).

\section{Effects of Calves' Breed}

Breed did not affect hematological variables measured $1 \mathrm{~d}$ before transport. In wk 2 posttransport, Holstein Friesian and Holstein Friesian $\times$ Belgian Blue crossbred calves had a higher monocyte count compared with other crossbred calves $\left(\Delta=2.06 \times 10^{9} / \mathrm{L} ; P=0.02\right.$; Table 3). One day before transport, N-IgM titers were higher in serum of Holstein Friesian $\times$ Belgian Blue calves compared with Holstein Friesian and other crossbred calves $(\Delta=0.43$ titer on average; $P=0.02$; Table 4). At the veal farm, N-IgA titers were lower in serum of Holstein Friesian $\times$ Belgian Blue calves compared with Holstein Friesian and other crossbred calves $(\Delta$ $=-0.23$ titer on average; $P=0.02$; Table 9). Breed did not have a statistically significant influence on N-Ig titers in colostrum and in serum samples of cows.

\section{Effects of Parity}

First-parity cows showed lower amounts of serum $\mathrm{N}-\mathrm{IgG}$, N-IgM, and N-IgA 1 wk before calving compared with higher parity cows (all $P<0.01$; Table 6). Colostrum obtained from first-parity cows had lower N-IgG, N-IgM, and N-IgA titers (all $P<0.05$; Table 7) compared with colostrum of older parity cows. Calves born from first-parity cows showed lower serum N-IgG $(P<0.01)$ and $\mathrm{N}-\mathrm{IgA}$ titers $(P=0.02)$ in wk 1 after birth, and lower serum N-IgG titers $1 \mathrm{~d}$ before transport and at the veal farm compared with calves born from cows of higher parities (Tables 8,10 , and 11). One day before transport, calves born from first-parity cows had lower serum eosinophil proportions compared with calves born from higher-parity cows $(P<0.01$; Supplemental Table S2, https://doi.org/10.6084/m9.figshare .16940611), but in wk 2 posttransport no statistically significant effects of parity on hematological profile were present (see Supplemental Table S3, https://doi .org/10.6084/m9.figshare.16940611).

\section{Effects of Ease of Birth}

One day before transport, calves that were born with the assistance of the farmers had more eosinophils $(\Delta=$ $0.10 \%)$ in their serum $(P<0.01$; Table 2 , Supplemental Table S2) compared with calves that were born without assistance. The birth process did not have a statistically significant effect on N-Ig titers in colostrum and serum.

\section{Effects of Calf and Cow Characteristics on Birth Weight of Calves}

Calves delivered by first-parity cows had a lower birth weight $(41.4 \mathrm{~kg})$ compared with calves delivered by multiparous cows $(43.6 \mathrm{~kg}$ for second parity cows, $45.3 \mathrm{~kg}$ for third parity cows, and $46.1 \mathrm{~kg}$ for cows with parity $4-10 ; P<0.01)$. Birth weight was higher for calves born with assistance during birth compared with calves born with a normal delivery $(\Delta=2 \mathrm{~kg}, P<$ 0.01). Additionally, crossbred calves (Holstein Friesian $\times$ Belgian Blue and other crossbreds) were heavier at birth compared with Holstein Friesian calves $(\Delta=3.5$ $\mathrm{kg}$ on average, $P<0.01$ ). Birth weight of bull calves was also higher than that of female calves $(\Delta=4.3 \mathrm{~kg}$, $P<0.01)$. In the current study $\mathrm{N}-\mathrm{Ig}$ was not affected by DPL or number of days open. Birth weight of calves was not affected by the DPL of their dams $(P=0.13)$.

Table 5. Effects of sampling moment and the interaction between sampling moment and transport age on immunoglobulin titers specific for phosphorylcholine conjugated to BSA measured in serum of calves at the veal farm (LSM \pm SEM)

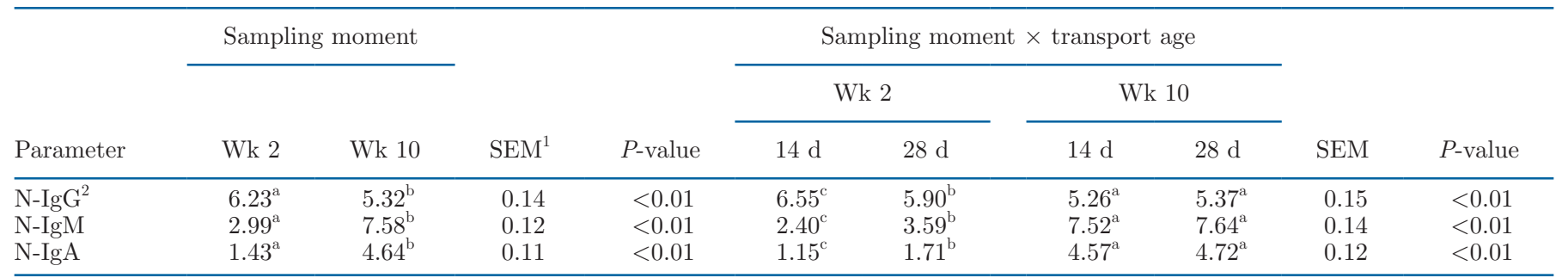

${ }^{\mathrm{a}-\mathrm{C}} \mathrm{LSM}$ within a factor and row lacking a common superscript differ $(P \leq 0.05)$.

${ }^{1} \mathrm{SEM}=$ pooled standard error.

${ }^{2} \mathrm{~N}=$ natural antibodies. 
Marcato et al.: EFFECTS OF TRANSPORT AGE ON IMMUNITY OF VEAL CALVES
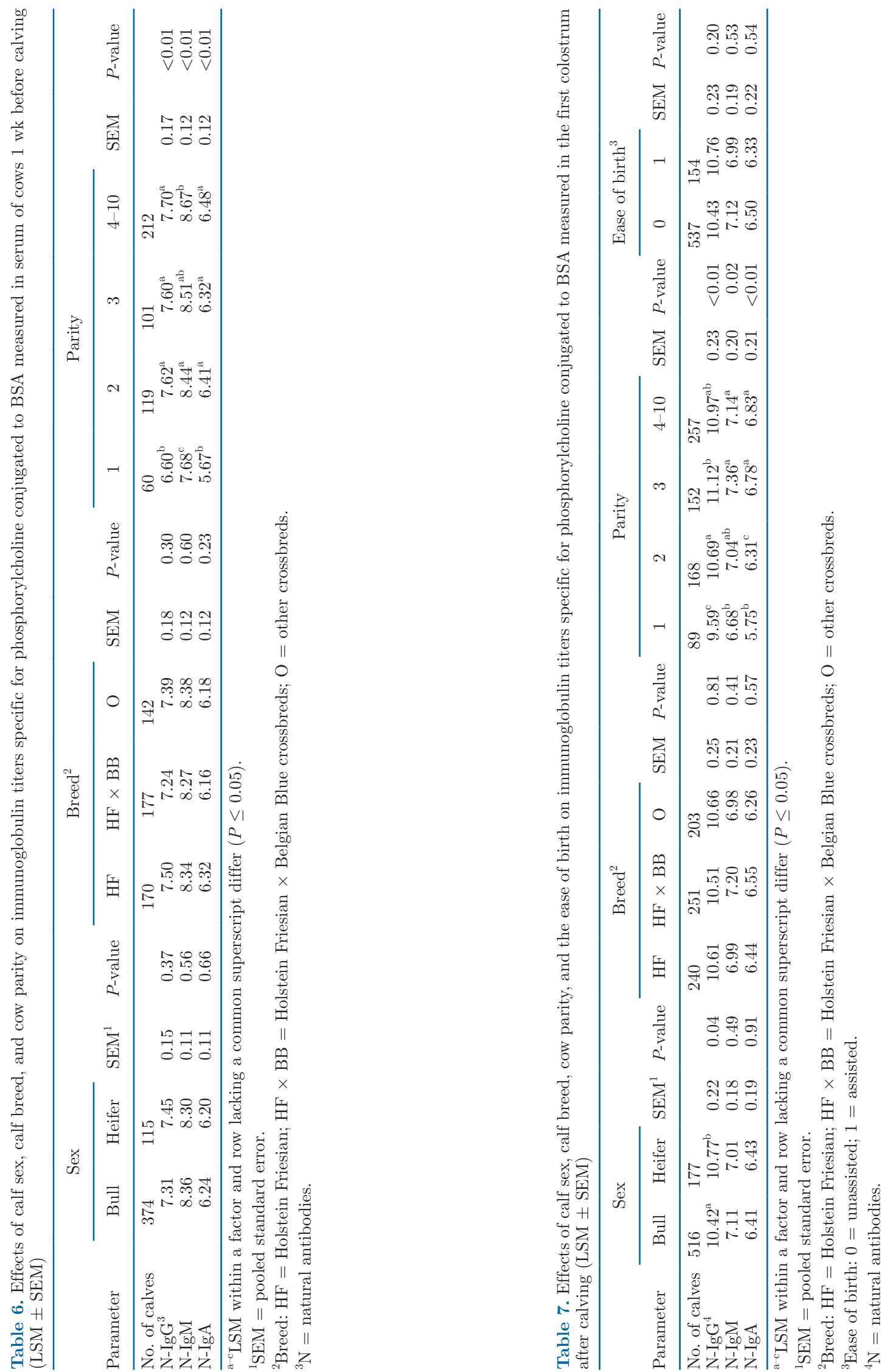
Marcato et al.: EFFECTS OF TRANSPORT AGE ON IMMUNITY OF VEAL CALVES
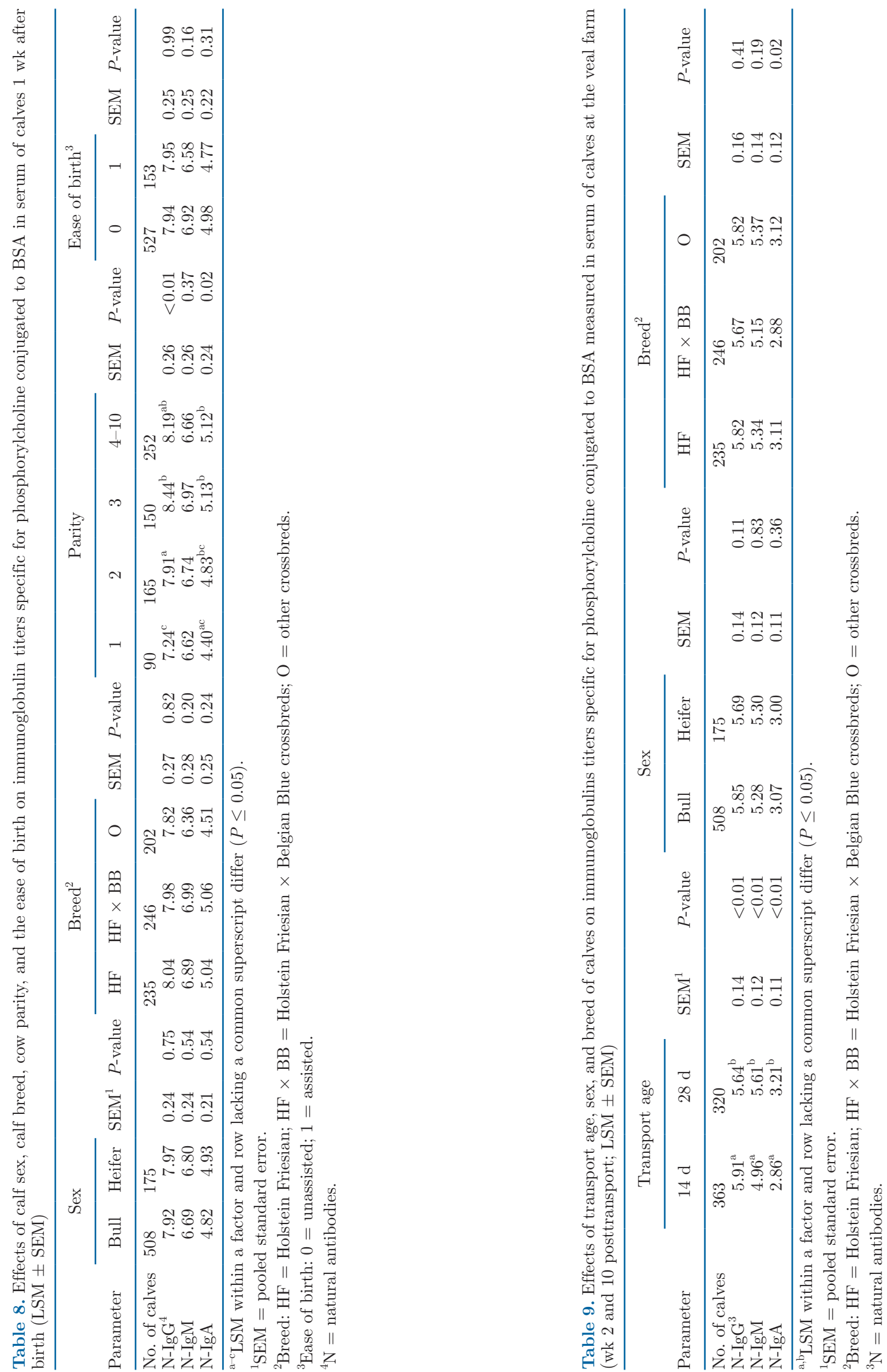
Table 10. Effects of parity of cows and ease of birth on immunoglobulin titers specific for phosphorylcholine conjugated to BSA measured in serum of calves $1 \mathrm{~d}$ before transport to the veal farm at d 14 or 28 of age (LSM \pm SEM)

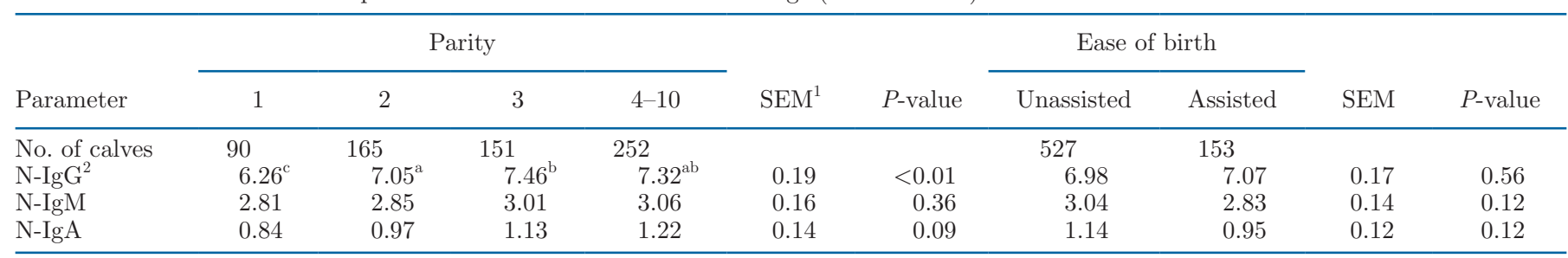

${ }^{\mathrm{a}-\mathrm{C}} \mathrm{LSM}$ within a factor and row lacking a common superscript differ $(P \leq 0.05)$.

${ }^{1} \mathrm{SEM}=$ pooled standard error.

${ }^{2} \mathrm{~N}=$ natural antibodies.

\section{Relationships Between Measures}

Table 12 shows the regression coefficients $(\beta)$ of relations between N-Ig in serum samples of calves (as response variables) and $\mathrm{N}-\mathrm{Ig}$ in colostrum or in serum samples of cows (as the explanatory variable). In wk 1 and $1 \mathrm{~d}$ before transport, all $3 \mathrm{~N}-\mathrm{Ig}$ isotypes of calves were positively related to N-Ig in colostrum $(P<0.05)$, and only N-IgG of calves was positively related to N-IgG in cow serum samples $(P<0.01)$. At the veal farm, N-IgG of calves was positively related to N-IgG in colostrum and N-IgG in serum of cows $(P<0.01)$.

Table 13 shows the regression coefficients $(\beta)$ of relations between $\mathrm{N}-\mathrm{Ig}$ in calf serum in wk 1 after birth, $1 \mathrm{~d}$ before transport, or in wk 2 at the veal farm, and the likelihood of a calf being individually treated with antibiotics or other medicines at the veal farm. All N-Ig titers in wk 1 at the dairy farm were negatively related to the likelihood of calves of being individually treated with antibiotics or other medicines at the veal farm. Additionally, only N-IgG titers measured in calf serum the day before transport and in wk 2 posttransport were negatively related to the likelihood of being individually treated with antibiotics or other medicines at the veal farm. Relationships between N-Ig in calf serum and carcass weight of calves were never statistically significant.
Regression coefficients shown in Tables 12 and 13 represent the coefficients obtained from regression models without interaction terms [i.e., on the assumption of homogeneity of regression slopes (slopes are parallel for different ages of transport, parity groups, sexes, and breeds)]. Some of the interactions were statistically significant, but they always reflected proportional differences between levels of a fixed effect in the strength of the relationship between the response variable and the covariable.

\section{DISCUSSION}

\section{Effects of Transport Age}

In the current study the hematological profile of calves was affected by transport age, although the observed values remained within the reference values of calves (Knowles et al., 2000). This is in line with previous studies, which indicated that age is a key factor for changes in hematological values, especially in the first weeks after the birth of calves (Brun-Hansen et al., 2006; Panousis et al., 2018). At 2 wk of age, which coincided with the transport of the 14-d treatment calves, values of $\mathrm{MCV}, \mathrm{MCH}$, WBC, neutrophils, and monocytes were higher compared with values at 4 wk of age, which coincided with transport of the

Table 11. Effects of parity of cows and ease of birth on immunoglobulin titers specific for phosphorylcholine conjugated to BSA measured in serum of calves at the veal farm (wk 2 and 10 posttransport; LSM $\pm \mathrm{SEM})^{1}$

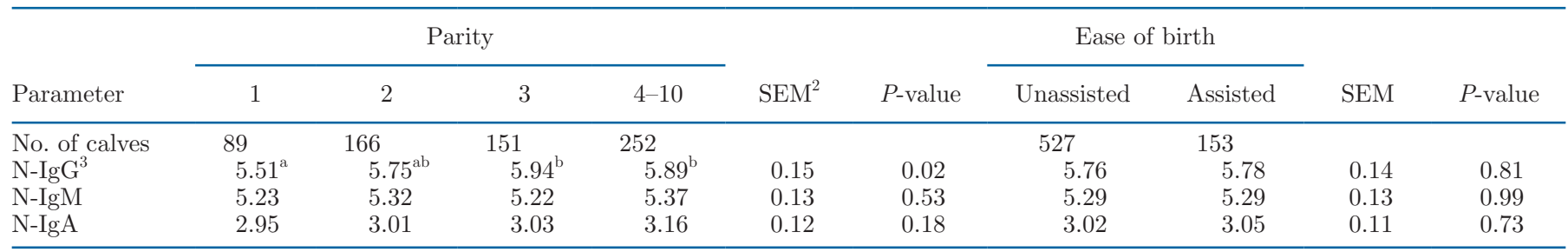

${ }^{\mathrm{a}, \mathrm{b}} \mathrm{LSM}$ within a factor and row lacking a common superscript differ $(P \leq 0.05)$.

${ }^{1}$ Calves were transported at 14 or $28 \mathrm{~d}$ of age.

${ }^{2} \mathrm{SEM}=$ pooled standard error.

${ }^{3} \mathrm{~N}=$ natural antibodies. 
Table 12. Regression coefficients ( $\beta$ ), SE (in parentheses), and significance values of relationships between immunoglobulins measured in colostrum and cow serum samples and those measured in serum of calves in wk $1,1 \mathrm{~d}$ before transport, and at the veal farm

\begin{tabular}{lll}
\hline & & Explanatory variable \\
\cline { 3 - 3 } Response variable & Colostrum & Cow serum \\
\hline Immunoglobulins measured in wk 1 & & \\
N-IgG & & $\beta=0.364(0.06), P<0.001$ \\
N-IgM & $\beta=0.614(0.06), P<0.001$ & $\beta=0.542(0.09), P<0.001$ \\
N-IgA & $\beta=0.576(0.07), P<0.001$ & $\beta=0.639(0.10), P<0.001$ \\
Immunoglobulins measured 1 d before transport & $\beta=0.571(0.06), P<0.001$ & \\
N-IgG & $\beta=0.620(0.06), P<0.001$ & $\beta=0.385(0.05), P<0.001$ \\
N-IgM & $\beta=0.171(0.06), P=0.002$ & $\beta=0.199(0.08), P=0.01$ \\
N-IgA & $\beta=0.170(0.05), P<0.001$ & $\beta=0.154(0.08), P=0.05$ \\
Immunoglobulins measured at the veal farm (wk 2 posttransport) & $\beta=0.676(0.05), P<0.001$ & $\beta=0.370(0.05), P<0.001$ \\
N-IgG & $\beta=0.066(0.07), P=0.33$ & $\beta=0.086(0.09), P=0.34$ \\
N-IgM & $\beta=0.090(0.04), P=0.03$ & $\beta=0.086(0.06), P=0.17$ \\
N-IgA & & \\
Immunoglobulins measured at the veal farm (wk 10 posttransport) & $\beta=0.189(0.05), P<0.001$ & $\beta=0.092(0.05), P=0.05$ \\
N-IgG & $\beta=-0.030(0.05), P=0.59$ & $\beta=-0.050(0.06), P=0.41$ \\
N-IgM & $\beta=-0.002(0.04), P=0.96$ & $\beta=0.018(0.06), P=0.77$ \\
N-IgA & &
\end{tabular}

${ }^{1} \mathrm{~N}=$ natural antibodies.

28 -d treatment. These results are in accordance to previous studies, which indicated that these changes might reflect the replacement of $\mathrm{RBC}$ containing fetal hemoglobin $(\mathrm{HgbF})$ with smaller RBC containing the adult type (HgbA; Egli and Blum, 1998; Brun-Hansen et al., 2006) and the progressively decreasing cortisol concentrations after birth (Knowles et al., 2000; Mohri et al., 2007). The lymphocyte count followed an opposite trend compared with neutrophil count. This is also in line with previous studies that reported a gradual increase in lymphocytes until 10 to 12 wk of age in calves (Brun-Hansen et al., 2006). All these changes, and in particular the higher lymphocyte and lower neutrophil counts, might contribute to improved immune responses in calves transported at $28 \mathrm{~d}$ compared with calves transported at $14 \mathrm{~d}$. von Konigslow et al. (2020) showed that lymphocyte counts between 4.6 and $5.8 \times$ $10^{9} / \mathrm{L}$ were associated with a lower hazard of mortality compared with lymphocyte counts $<4.6$ or $>5.8 \times$ $10^{9} /$ L. Additionally, lymphocyte counts $>5.8 \times 10^{9} / \mathrm{L}$ reduced the hazard of morbidity of calves upon arrival at the veal farm compared with lymphocyte counts $<5.8 \times 10^{9} / \mathrm{L}$, and elevated neutrophil counts $(>6.0$ $\times 10^{9} / \mathrm{L}$ ) increased the hazard of mortality by more than 5 times. These authors proposed that especially an elevated lymphocyte count $\left(>7 \times 10^{9} / \mathrm{L}\right)$ might be used as an indicator of resilience to stress, in particular related to transport. These findings may, therefore, suggest that calves transported at $28 \mathrm{~d}$ of age might be more robust due to the fact that their adaptive im-

Table 13. Regression coefficients ( $\beta$ ), SE (in parentheses), and significance values of relationships between calf serum immunoglobulin titers measured at different time points and the probability of a calf being individually treated either with antibiotics or with other medicines during the whole rearing period at the veal farm

Response variable

\begin{tabular}{lll} 
Explanatory variable & Treatment with antibiotics & Treatment with other medicin \\
\cline { 3 - 3 } & & \\
\hline N-IgG & & \\
N-IgG_wk 1 after birth & $\beta=-0.196(0.06), P<0.001$ & $\beta=0.192(0.06), P<0.001$ \\
N-IgG_1 d before transport & $\beta=-0.235(0.07), P<0.001$ & $\beta=-0.212(0.06), P<0.001$ \\
N-IgG_wk 2 at the veal farm & $\beta=-0.253(0.06), P<0.001$ & $\beta=-0.196(0.06), P=0.001$ \\
N-IgM & $\beta=-0.165(0.06) ; P=0.03$ & $\beta=-0.136(0.06), P=0.01$ \\
N-IgM_wk 1 after birth & $\beta=-0.168(0.09), P=0.05$ & $\beta=-0.114(0.08), P=0.17$ \\
N-IgM_1 d before transport & $\beta=-0.04(0.06), P=0.57$ & $\beta=-0.03(0.07), P=0.66$ \\
N-IgM_wk 2 at the veal farm & $\beta=-0.148(0.06), P<0.01$ & $\beta=-0.132(0.06), P=0.02$ \\
N-IgA & $\beta=-0.160(0.10), P=0.14$ & $\beta=-0.08(0.10), P=0.43$ \\
N-IgA_wk 1 after birth & $\beta=0.04(0.09), P=0.68$ & $\beta=0.04(0.09), P=0.68$
\end{tabular}

${ }^{1}$ Treatment with antibiotics (or with other medicines) was expressed as binary measure $(0=$ calf not treated; $1=$ calf treated at least once). ${ }^{2} \mathrm{~N}=$ natural antibodies. 
mune system has matured compared with that from calves transported at $14 \mathrm{~d}$ of age. This idea is further substantiated in our companion paper (Marcato et al., 2022) looking at differences between the 2 transport age groups in putative measures of robustness recorded at the veal farm, including treatments with medicines, carcass weight, and mortality. The results of the regression analyses reported in the current study showed that, at least within age groups, differences between calves in cell counts were not associated with differences in individual antibiotic or other medical treatments or carcass weight, which seems to be in contrast with the results of von Konigslow et al. (2020). However, in their study, lymphocyte and neutrophil counts were correlated with morbidity and mortality rates of calves at the veal farm. As will be addressed in our companion paper (Marcato et al., 2022), these rates were relatively low in the current study.

One day before transport calves transported at 14 $\mathrm{d}$ of age had higher serum titers of all $3 \mathrm{~N}$-Ig isotypes compared with calves transported at $28 \mathrm{~d}$ of age. Since calves transported at $14 \mathrm{~d}$ were 2 wk younger than the other transport group, their serum immunoglobulins on the day before transport likely reflected maternal immunoglobulins obtained from colostrum to a greater extent than the serum of calves transported at $28 \mathrm{~d}$. It is indeed well known that the immune response of calves in the first weeks after birth largely relies on passive immunity transferred from their mothers via colostrum (Barrington and Parish, 2001; Stilwell and Carvalho, 2011). This is also reflected in a positive relationship between the titer of $\mathrm{N}-\mathrm{Ig}$ in colostrum and the N-Ig in the serum of calves measured $1 \mathrm{wk}$ after birth. Mayasari et al. (2016) found a positive relationship between the level of natural autoantibodies in plasma of calves in their first weeks of age and natural autoantibodies in colostrum, although this relationship was not maintained after 2 wk of age. The current study showed a positive relationship between N-IgG in serum of calves and N-IgG in colostrum, and this relationship was maintained until wk 2 at the veal farm, regardless of transport age. These results suggest that immune protection via maternal colostrum may last for a longer period. These long-term maternal effects might have a positive effect on robustness of calves at the veal farm, which was supported by the negative relationship between N-IgG in serum of calves and the number of individual antibiotic and other medical treatments at the veal farm. Two weeks after arrival at the veal farm, calves transported at $14 \mathrm{~d}$ of age showed lower serum N-IgM and N-IgA levels compared with calves transported at $28 \mathrm{~d}$. This difference between the 2 transport age groups might reflect the decline of passive immunity derived from colostrum in 14-d-old calves and the activation of endogenous Ig synthesis in 28-d-old calves (Burton et al., 1989; Chase et al., 2008). Thus, it is suggested that, at this time point and in comparison with calves transported at $14 \mathrm{~d}$, differences in N-IgM and N-IgA titers between calves transported at $28 \mathrm{~d}$ were not only quantitative but also qualitative in nature. Probably a larger part of the N-IgM and N-IgA antibodies in calves transported at $28 \mathrm{~d}$ of age were directed specifically against pathogens present at the veal farm, thereby providing better protection against infection and disease during the early, and vulnerable, stages after arrival at the veal farm. The immune system of calves in the first weeks after birth is still immature and requires time to complete development (Gomes et al., 2014). According to Chase et al. (2008), endogenous production of IgM in calves starts reaching functional levels around $8 \mathrm{~d}$ of age, whereas levels of endogenous IgG and $\operatorname{IgA}$ do not reach functional levels until 16 to $32 \mathrm{~d}$ after birth. Since the adaptive immunity of calves is not completely developed yet, maternal antibodies in colostrum provide neonatal calves passive immunity and protection in the first 2 wk after birth (Hassig et al., 2007; Yang et al., 2015). Burton et al. (1989) showed that peak concentrations of $\operatorname{IgG}, \operatorname{IgM}$, and $\operatorname{IgA}$ in serum of calves occurred at 24 to $36 \mathrm{~h}$ after birth $(1,801,154$, and 110 $\mathrm{mg} / 100 \mathrm{~mL}$, respectively) and were associated with colostrum intake. The minimum serum concentrations of these immunoglobulins were found at $3 \mathrm{wk}$ of age for $\operatorname{IgM}(36 \mathrm{mg} / 100 \mathrm{~mL})$ and $\operatorname{IgA}(27 \mathrm{mg} / 100 \mathrm{~mL})$ and at $4 \mathrm{wk}$ for $\operatorname{IgG}(1,213 \mathrm{mg} / 100 \mathrm{mg})$. After these moments, concentrations of all 3 isotypes gradually increased as a result of endogenous production (Burton et al., 1989). In the current experiment, the patterns over time of serum N-IgM and N-IgA titers were also in line with previous research; thus, calves transported at $28 \mathrm{~d}$ were older at arrival at the veal farm and this explains their higher N-IgM and N-IgA titers compared with calves transported at $14 \mathrm{~d}$ of age. When comparing the titers of immunoglobulins in serum of calves measured in wk 1 after birth and $1 \mathrm{~d}$ before transport with the titers measured in wk 2 and wk 10 posttransport, it is evident that the lowest N-IgM and N-IgA titers occurred at the age of $4 \mathrm{wk}$ (i.e., in wk 2 posttransport in calves transported at $14 \mathrm{~d}$ of age, and $1 \mathrm{~d}$ before transport in calves transported at $28 \mathrm{~d}$ of age). The lowest N-IgG titers were obtained in wk 10 posttransport (i.e., when calves in the 2 transport age groups were 12 and 14 wk old, respectively), and until that time the level of $\mathrm{N}-\mathrm{IgG}$ seemed to only moderately decrease. This particular pattern for N-IgG was shown by both transport age groups, and it notably differs from what is described in the literature. Perhaps, endogenous IgG production was more pronounced in our calves compared with 
other (e.g., replacement heifer) calves, for example because their adaptive immune system was stimulated to a greater extent, in particular after arrival at the veal farm. However, in the current study, no discrimination was made between N-IgG of maternal or endogenous origin. Future research is, therefore, needed to further characterize patterns over time of immunoglobulins in veal calves.

Our results clearly underline the importance of feeding high-quality colostrum to calves. In fact, the amount of N-Ig in colostrum had a long-term influence on the amount of N-Ig in serum of calves. Moreover, the N-IgG concentration in calf serum might be used as an indicator of robustness, because N-IgG titers were negatively related to the likelihood of calves being individually treated with antibiotics or other medicines at the veal farm. On the basis of the levels of N-Ig measured in wk 2 at the veal farm, transportation of calves 2 wk later than the usual practice might be more appropriate, because the development of their adaptive immunity was more advanced. However, more research is needed to define what is the optimal transport age of calves. Perhaps a transport age considerably older than $28 \mathrm{~d}$ (such as 6,8 , or even 12 wk of age) might also be suboptimal for the health status of calves because then they are reared for a longer period on a dairy farm and when they are transported to a veal farm their immune system might be less adjusted to the new environment than the immune system of calves that have been able to develop the appropriate environment-specific adaptive immunity for a longer period of time. Given the present finding, N-IgG should be monitored also in the period between wk 2 and 10 posttransport, and beyond. This would allow to (1) determine the proportions of maternal and endogenous IgG over this time frame, (2) determine when the adaptive immune system of calves becomes functional, and (3) investigate whether or not N-IgG titers continue to decrease or reach a plateau beyond wk 10 posttransport.

\section{Effects of Calves' Sex}

Effects of calf sex on hematological profile are not extensively investigated and they are often controversial. Tennant et al. (1974) did not observe any sex-related differences in calves, whereas Raleigh and Wallace (1962) found higher hemoglobin and hematocrit values in female calves from birth to 25 wk of age than in male calves.

In the current study, female calves had a higher hemoglobin, hematocrit, and RBC compared with bull calves $1 \mathrm{~d}$ before transport. These results are in line with the study of Panousis et al. (2018), although they included only Holstein Friesian calves between 1 and
9 d of age. Differences between hematological characteristics in female calves compared with bull calves might be related to a different hormonal status or to a difference in birth weight between bull and female calves (46.2 vs. $41.9 \mathrm{~kg}$, respectively). In the companion paper (Marcato et al., 2022), effects of sex on health, medicine use at the veal farm, and carcass weight are investigated to understand whether or not there is a difference in robustness between bull and female calves.

\section{Effects of Calves' Breed}

The hematological profile of calves has been studied in both beef (Adams et al., 1992; Egli and Blum, 1998) and dairy breeds, especially Holstein Friesian calves (Mohri et al., 2007; Panousis et al., 2018). In the current study, hematological variables did not differ among breeds. This was in contrast with previous studies that indicated differences in blood variables (such as hemoglobin and hematocrit) between dairy and beef breeds. With regard to $\mathrm{N}-\mathrm{Ig}$, Belgian Blue $\times$ Holstein Friesian calves had the highest N-IgM titers $1 \mathrm{~d}$ before transport and the lowest N-IgA titers at the veal farm compared with the other breeds. Although not statistically significant, the other N-Ig titers followed the same pattern as N-IgM and N-IgA at both time points, respectively. These results might be an indication that the immunity gap occurs at a later stage for Belgian Blue $\times$ Holstein Friesian calves compared with the other breeds. Higher N-Ig at the time of transport might be related to an improved robustness of calves upon arrival at the veal farm. This is investigated in the companion paper (Marcato et al., 2022), looking at effects of breed on measures of robustness in the long term.

\section{Effects of Parity}

Parity had the most evident effects on N-Ig titers measured in cow samples, colostrum, and calf samples in wk 1 after birth, whereas parity affected only N-IgG titers measured $1 \mathrm{~d}$ before transport and at the veal farm. Results indicated higher N-Ig titers in older parity cows compared with first-parity cows, and this is in line with previous studies. Older cows are likely to be exposed to a greater number of pathogenic antigens in their lifetime, which is likely the cause for higher immunoglobulin titers in their serum and, sequentially, in colostrum (Conneely et al., 2013). Tyler et al. (1999) reported that colostrum produced by cows of parity 3 or higher contained $19.5 \mathrm{~g}$ of $\mathrm{IgG} / \mathrm{L}$ more compared with colostrum produced by primiparous cows. Aydogdu and Guzelbektes (2018) also showed that colostrum of multiparous cows had a higher IgG concentration 
than colostrum produced by primiparous cows (117.4 vs. $73.8 \mathrm{~g} / \mathrm{L}$, respectively). Another reason for the higher immunoglobulin concentration in colostrum of multiparous cows might be related to the development of the mammary gland. As indicated by Dunn et al. (2017), younger cows might be not fully developed and the transport of immunoglobulins from the blood circulation into the mammary gland may be reduced compared with older cows. Effects of parity were still evident on N-IgG titers measured in serum of calves 10 wk posttransport, which is a long period after colostrum intake. The relationships between N-Ig titers, especially $\mathrm{N}-\mathrm{IgG}$, in serum of calves and the ones in colostrum and serum of cows indicate a clear connection between calves and their mothers. These results are in line with those shown by Mayasari et al. (2016), who suggested that the level of natural autoantibodies in the plasma of calves in the first $2 \mathrm{wk}$ after birth reflects the levels of natural autoantibodies in colostrum and in plasma of cows. In that study, this relationship was not maintained beyond wk 2, whereas in the current study the relationship was maintained until wk 10 posttransport. All these findings suggest that the pre- and postnatal period play an important role on the immune development of calves and farmers should provide good-quality colostrum to increase the immunoglobulin content in serum of calves. Additionally, pasteurized colostrum obtained from older cows might confer more protection to calves via passive immunity.

\section{Effects of Calving Process}

The calving process is known to have profound effects on hematological profile and immune system of newborn calves (Probo et al., 2012). A longer delivery requiring assistance of the farmer can result in higher levels of WBC, neutrophils, hemoglobin, hematocrit, and $\mathrm{RBC}$ in in calves. All these observations were done on newborn calves and there is scarce information on the association between the ease of birth and hematological profile and immune system in older calves for veal production. In the current study, ease of birth did not influence the hematological profile. Additionally, $\mathrm{N}-\mathrm{Ig}$ titers of calves at different time points were not influenced by ease of birth. To assess whether or not the calving process has long-term consequences on robustness of calves, the companion paper (Marcato et al., 2022) describes effects of ease of birth on health and performance of calves at the veal farm.

\section{Effects of Other Cow-Related Characteristics}

Factors such as DPL, milk yield, and days open of dairy cows have been shown to play an important role on the prenatal life of calves (Van Eetvelde and Opsomer, 2020). Prenatal conditions can affect the developmental programming of later health and performance of calves (Astiz et al., 2014; Pinedo and De Vries, 2017). For example, high milk yield during pregnancy leads to a significant loss of nutrients (e.g., protein and glucose) for the fetus, because they are diverted to the mammary gland rather than to the uterus (Opsomer et al., 2016). This in turn affects the birth weight of the calf, and high-producing cows (with cumulative milk production during gestation between 7,200 and 11,600 $\mathrm{kg}$ ) have been shown to deliver 1-kg lighter calves than low-producing cows (Kamal et al., 2014). Because milk yield affects protein partitioning to the fetus, the current study investigated whether or not milk yield also affected immunoglobulin production in calves. In the current study immunoglobulins were not affected by DPL or number of days open. Although not statistically significant, calves born from cows with a shorter dry period $(0-30 \mathrm{~d})$ had a lower birth weight $(42.6 \mathrm{~kg})$ compared with calves born from cows with a longer dry period (44.6 $\mathrm{kg}$ for cows with $30-60 \mathrm{~d}$, and 45.5 for cows with $>60 \mathrm{~d}$ ). Additionally, calves delivered by first-parity cows had a lower birth weight compared with calves delivered by multiparous cows. These findings are supported by previous studies, where a shorter DPL and primiparity of cows contributed to a lower birth weight of calves (Kamal et al., 2014; Van Eetvelde and Opsomer, 2020). A shorter dry period is often used for high-yielding cows with high lactation persistency; thus, as explained above, high milk yield might have a negative effect on fetal development (Van Eetvelde and Opsomer, 2020). In first-parity cows, pregnancy coincides with continued growth of the dam; thus, the fetus might face competition with the nutrients the mother needs for her own development (Opsomer et al., 2016). The current study showed that maternal characteristics can affect calf characteristics at birth. Long-term consequences of birth weight on measures of robustness recorded at the veal farm, including treatments with medicines and carcass weight, are described in our companion paper (Marcato et al., 2022).

\section{CONCLUSIONS}

Transportation of calves at the range of ages studied in the present experiment still occurs in the immune gap period. However, it appears that calves transported at $28 \mathrm{~d}$ of age had higher N-IgM and N-IgA titers in wk 2 posttransport in comparison with calves transported at $14 \mathrm{~d}$ of age, which might be interpreted as a sign of a more advanced development of their adaptive immunity. However, more research is needed to define the optimal age to transport calves from the dairy farm to the veal 
farm. Feeding high-quality colostrum appears to have important long-term consequences on the immunity of veal calves because colostrum N-Ig titers, in particular $\mathrm{N}-\mathrm{IgG}$, were positively related to high N-Ig titers in serum of calves, even 2 wk after arrival at the veal farm. High N-IgG titers in calf serum were associated with a reduced likelihood of calves being individually treated with antibiotics or other medicines at the veal farm, which might be an indication of improved robustness.

\section{ACKNOWLEDGMENTS}

This study was financially supported by Stichting Brancheorganisatie Kalversector (SBK, Nieuwegein, the Netherlands), ZuivelNL (the organization of the Dutch dairy sector, Den Haag, the Netherlands), and the Dutch Ministry of Agriculture, Nature and Food Quality (Den Haag, the Netherlands). The authors gratefully acknowledge Rimondia B.V. (Elspeet, the Netherlands) for providing personnel and laboratory support and Rudie Koopmanschap, Joop Aarts, and Ilona van den Anker (Adaptation Physiology Group, Wageningen University \& Research, Wageningen, the Netherlands), and Conny van Solt and Corry Dolstra (Wageningen Bioveterinary Research, Lelystad, the Netherlands) for their skilled technical and laboratory assistance. The authors are also very grateful to all dairy and veal farmers who contributed to this experiment, to Van 't Slot Veetransport (Elspeet, the Netherlands) for expertly transporting the calves, and to Yvonne Daandels of ZLTO (Den Bosch, the Netherlands), AERES Hogeschool Dronten (Dronten, the Netherlands), HAS Hogeschool (Den Bosch, the Netherlands), Gerald Lock, Dirk Anjema, and Harmen Kremers of Wageningen Bioveterinary Research (Lelystad, the Netherlands), and Theo van Hattum, Henk Gunnink, Joop van der Werf, Laura Arango Carmona, Amelia Florida Kiha, and Hao Ye (Wageningen University \& Research, Wageningen, the Netherlands) for their help and assistance during the experiment. Moreover, the authors acknowledge two anonymous reviewers for their valuable comments to previous versions of this paper. The authors have not stated any conflicts of interest.

\section{REFERENCES}

Adams, R., F. B. Garry, B. M. Aldridge, M. D. Holland, and K. G. Odde. 1992. Hematologic values in newborn beef calves. Am. J. Vet. Res. 53:944-950.

Astiz, S., A. Gonzalez-Bulnes, F. Sebastian, O. Fargas, I. Cano, and P. Cuesta. 2014. Maternal aging affects life performance of progeny in a Holstein dairy cow model. J. Dev. Orig. Health Dis. 5:374-384. https://doi.org/10.1017/S2040174414000361.

Aydogdu, U., and H. Guzelbektes. 2018. Effect of colostrum composition on passive calf immunity in primiparous and multiparous dairy cows. Vet. Med. (Praha) 63:1-11. https://doi.org/10.17221/ 40/2017-VETMED.
Barrington, G. M., and S. M. Parish. 2001. Bovine neonatal immunology. Vet. Clin. North Am. Food Anim. Pract. 17:463-476. https:/ /doi.org/10.1016/S0749-0720(15)30001-3.

Bartier, A. L., M. C. Windever, and L. Doepel. 2015. Evaluation of on-farm tools for colostrum quality measurement. J. Dairy Sci. 98:1878-1884. https://doi.org/10.3168/jds.2014-8415.

Brun-Hansen, H. C., A. H. Kampen, and A. Lund. 2006. Hematologic values in calves during the first 6 months of life. Vet. Clin. Pathol. 35:182-187. https://doi.org/10.1111/j.1939-165X.2006.tb00111.x.

Burton, J. L., B. Kennedy, E. Burnside, B. Wilkie, and J. Burton. 1989. Variation in serum concentrations of immunoglobulins G, A and $\mathrm{M}$ in Canadian Holstein-Friesian calves. J. Dairy Sci. 72:135149. https://doi.org/10.3168/jds.S0022-0302(89)79089-5.

Chase, C. C., D. J. Hurley, and A. J. Reber. 2008. Neonatal immune development in the calf and its impact on vaccine response. Vet. Clin. North Am. Food Anim. Pract. 24:87-104. https://doi.org/10 .1016/j.cvfa.2007.11.001.

Colditz, I. G., and B. C. Hine. 2016. Resilience in farm animals: Biology, management, breeding and implications for animal welfare. Anim. Prod. Sci. 56:1961-1983. https://doi.org/10.1071/AN15297.

Conneely, M., D. Berry, R. Sayers, J. Murphy, I. Lorenz, M. Doherty, and E. Kennedy. 2013. Factors associated with the concentration of immunoglobulin G in the colostrum of dairy cows. Animal 7:1824-1832. https://doi.org/10.1017/S1751731113001444.

de Almeida, A. M., M. Zachut, L. E. Hernández-Castellano, M. Šperanda, G. Gabai, and A. Mobasheri. 2019. Biomarkers of fitness and welfare in dairy animals: Healthy living. J. Dairy Res. 86:379-387. https://doi.org/10.1017/S0022029919000803.

Dunn, A., A. Ashfield, B. Earley, M. Welsh, A. Gordon, and S. Morrison. 2017. Evaluation of factors associated with immunoglobulin $\mathrm{G}$, fat, protein, and lactose concentrations in bovine colostrum and colostrum management practices in grassland-based dairy systems in Northern Ireland. J. Dairy Sci. 100:2068-2079. https://doi.org/ 10.3168/jds.2016-11724.

Egli, C. P., and J. Blum. 1998. Clinical, haematological, metabolic and endocrine traits during the first three months of life of suckling Simmentaler calves held in a cow-calf operation. J. Vet. Med. A Physiol. Pathol. Clin. Med. 45:99-118. https://doi.org/10.1111/j .1439-0442.1998.tb00806.x.

Engel, B., W. Buist, and C. G. van Reenen. 2016. Housing of calves in experimental facilities in relation to accuracy of comparison of feed rations in terms of confidence interval length and power of a significance test. Confidential report, commissioned by Denkavit Nederland BV.

Godden, S. M., J. P. Fetrow, J. M. Feirtag, L. R. Green, and S. J. Wells. 2005. Economic analysis of feeding pasteurized nonsaleable milk versus conventional milk replacer to dairy calves. J. Am. Vet. Med. Assoc. 226:1547-1554. https://doi.org/10.2460/javma.2005 .226 .1547

Goetz, H. M., D. F. Kelton, J. H. C. Costa, C. B. Winder, and D. L. Renaud. 2021. Identification of biomarkers measured upon arrival associated with morbidity, mortality, and average daily gain in grain-fed veal calves. J. Dairy Sci. 104:874-885. https://doi.org/10 .3168/jds.2020-18729.

Gomes, V., C. Baccili, V. Baldacim, K. Madureira, A. Guilloux, C. Pozzi, and C. Gomes. 2014. Development of the innate immune response and influence of colostrum suckling in calves. Am. J. Anim. Vet. Sci. 9:77-83. https://doi.org/10.3844/ajavsp.2014.77.83.

Hassig, M., T. Stadler, and H. Lutz. 2007. Transition from maternal to endogenous antibodies in newborn calves. Vet. Rec. 160:234-235 https://doi.org/10.1136/vr.160.7.234.

Kamal, M. M., M. Van Eetvelde, E. Depreester, M. Hostens, L. Vandaele, and G. Opsomer. 2014. Age at calving in heifers and level of milk production during gestation in cows are associated with the birth size of Holstein calves. J. Dairy Sci. 97:5448-5458. https:// doi.org/10.3168/jds.2014-7898.

Kenward, M. G., and J. H. Roger. 1997. Small sample inference for fixed effects from restricted maximum likelihood. Biometrics 53:983-997. https://doi.org/10.2307/2533558.

Knowles, T. G., S. N. Brown, J. E. Edwards, A. J. Phillips, and P. D. Warriss. 1999. Effect on young calves of a one-hour feeding stop 
during a 19-hour road journey. Vet. Rec. 144:687-692. https://doi .org/10.1136/vr.144.25.687.

Knowles, T. G., J. E. Edwards, K. Bazeley, S. N. Brown, A. Butterworth, and P. D. Warriss. 2000. Changes in the blood biochemical and haematological profile of neonatal calves with age. Vet. Rec. 147:593-598. https://doi.org/10.1136/vr.147.21.593.

Marcato, F., H. van den Brand, C. A. Jansen, V. P. M. G. Rutten, B. Kemp, B. Engel, M. Wolthuis-Fillerup, and K. van Reenen. 2021. Effects of pre-transport diet, transport duration and transport condition on immune cell subsets, haptoglobin, cortisol and bilirubin in young veal calves. PLoS One 16:e0246959. https://doi .org/10.1371/journal.pone.0246959.

Marcato, F., H. van den Brand, B. Kemp, B. Engel, S. Schnabel, F. Hoorweg, M. Wolthuis-Fillerup, and K. van Reenen. 2022. Effects of transport age and calf and maternal characteristics on health and performance of veal calves. J. Dairy Sci. 105:1452-1468. https: //doi.org/10.3168/jds.2021-20637.

Marcato, F., H. van den Brand, B. Kemp, B. Engel, M. WolthuisFillerup, and K. van Reenen. 2020a. Effects of pretransport diet, transport duration, and type of vehicle on physiological status of young veal calves. J. Dairy Sci. 103:3505-3520. https://doi.org/10 $.3168 /$ jds.2019-17445.

Marcato, F., H. van den Brand, B. Kemp, B. Engel, M. WolthuisFillerup, and K. van Reenen. 2020b. Transport of young veal calves: Effects of pre-transport diet, transport duration and type of vehicle on health, behavior, use of medicines, and slaughter characteristics. Front. Vet. Sci. 7:576469. https://doi.org/10.3389/ fvets.2020.576469.

Marcato, F., H. van den Brand, B. Kemp, and K. van Reenen. 2018. Evaluating potential biomarkers of health and performance in veal calves. Front. Vet. Sci. 5:133. https://doi.org/10.3389/fvets.2018 .00133

Masmeijer, C., B. Devriendt, T. Rogge, K. van Leenen, L. De Cremer, B. Van Ranst, P. Deprez, E. Cox, and B. Pardon. 2019. Randomized field trial on the effects of body weight and short transport on stress and immune variables in 2 -to 4 -week-old dairy calves. J. Vet. Intern. Med. 33:1514-1529. https://doi.org/10.1111/jvim.15482.

Mayasari, N., J. Chen, A. Ferrari, R. M. Bruckmaier, B. Kemp, H. K. Parmentier, A. T. M. van Knegsel, and E. Trevisi. 2017. Effects of dry period length and dietary energy source on inflammatory biomarkers and oxidative stress in dairy cows. J. Dairy Sci. 100:4961-4975. https://doi.org/10.3168/jds.2016-11857.

Mayasari, N., A. Van Knegsel, G. de Vries Reilingh, B. Kemp, and H. Parmentier. 2016. Natural autoantibodies in Bos taurus calves during the first twelve weeks of life. Vet. Immunol. Immunopathol. 178:70-78. https://doi.org/10.1016/j.vetimm.2016.07.001.

Mohri, M., K. Sharifi, and S. Eidi. 2007. Hematology and serum biochemistry of Holstein dairy calves: Age related changes and comparison with blood composition in adults. Res. Vet. Sci. 83:30-39. https://doi.org/10.1016/j.rvsc.2006.10.017.

Opsomer, G., M. Van Eetvelde, M. Kamal, and A. Van Soom. 2016. Epidemiological evidence for metabolic programming in dairy cattle. Reprod. Fertil. Dev. 29:52-57. https://doi.org/10.1071/ RD16410.

Panousis, N., N. Siachos, G. Kitkas, E. Kalaitzakis, M. Kritsepi-Konstantinou, and G. E. Valergakis. 2018. Hematology reference intervals for neonatal Holstein calves. Res. Vet. Sci. 118:1-10. https:// doi.org/10.1016/j.rvsc.2018.01.002.

Pardon, B., J. Alliet, R. Boone, S. Roelandt, B. Valgaeren, and P. Deprez. 2015. Prediction of respiratory disease and diarrhea in veal calves based on immunoglobulin levels and the serostatus for respiratory pathogens measured at arrival. Prev. Vet. Med. 120:169-176. https://doi.org/10.1016/j.prevetmed.2015.04.009.

Pinedo, P. J., and A. De Vries. 2017. Season of conception is associated with future survival, fertility, and milk yield of Holstein cows. J. Dairy Sci. 100:6631-6639. https://doi.org/10.3168/jds.2017-12662.

Pinkert, C. A., J. Manz, P. J. Linton, N. R. Klinman, and U. Storb. 1989. Elevated PC responsive B cells and anti-PC antibody production in transgenic mice harboring anti-PC immunoglobulin genes. Vet. Immunol. Immunopathol. 23:321-332. https://doi.org/ 10.1016/0165-2427(89)90144-X.
Ploegaert, T. C. W., G. De Vries Reilingh, M. G. B. Nieuwland, A. Lammers, H. F. J. Savelkoul, and H. K. Parmentier. 2007. Intratracheally administered pathogen-associated molecular patterns affect antibody responses of poultry. Poult. Sci. 86:1667-1676. https://doi.org/10.1093/ps/86.8.1667.

Probo, M., A. Giordano, P. Moretti, G. Opsomer, L. Fiems, and M. Veronesi. 2012. Mode of delivery is associated with different hematological profiles in the newborn calf. Theriogenology 77:865-872. https://doi.org/10.1016/j.theriogenology.2011.09.010.

Quigley, J. D., A. Lago, C. Chapman, P. Erickson, and J. Polo. 2013. Evaluation of the Brix refractometer to estimate immunoglobulin G concentration in bovine colostrum. J. Dairy Sci. 96:1148-1155. https://doi.org/10.3168/jds.2012-5823.

Raleigh, R. J., and J. Wallace. 1962. The influence of iron and copper on hematologic values and on body weight of range calves. Am. J. Vet. Res. 23:296-299.

Renaud, D. L., T. F. Duffield, S. J. LeBlanc, S. Ferguson, D. B. Haley, and D. F. Kelton. 2018a. Risk factors associated with mortality at a milk-fed veal calf facility: A prospective cohort study. J. Dairy Sci. 101:2659-2668. https://doi.org/10.3168/jds.2017-13581.

Renaud, D. L., T. F. Duffield, S. J. LeBlanc, D. B. Haley, and D. F. Kelton. 2018b. Clinical and metabolic indicators associated with early mortality at a milk-fed veal facility: A prospective case-control study. J. Dairy Sci. 101:2669-2678. https://doi.org/10.3168/ jds.2017-14042.

Roland, L., M. Drillich, D. Klein-Jöbstl, and M. Iwersen. 2016. Invited review: Influence of climatic conditions on the development, performance, and health of calves. J. Dairy Sci. 99:2438-2452. https: //doi.org/10.3168/jds.2015-9901.

Scott, K., D. F. Kelton, T. F. Duffield, and D. L. Renaud. 2019. Risk factors identified on arrival associated with morbidity and mortality at a grain-fed veal facility: A prospective, single-cohort study. J. Dairy Sci. 102:9224-9235. https://doi.org/10.3168/jds.2019-16829.

Stilwell, G., and R. C. Carvalho. 2011. Clinical outcome of calves with failure of passive transfer as diagnosed by a commercially available N-IgG quick test kit. Can. Vet. J. 52:524-526.

Tennant, B., D. Harrold, M. Reina-Guerra, J. W. Kendrick, and R. C. Laben. 1974. Hematology of the neonatal calf: Erythrocyte and leukocyte values of normal calves. Cornell Vet. 64:516-532.

Tyler, J. W., B. J. Steevens, D. E. Hostetler, J. M. Holle, and J. Denbigh Jr.. 1999. Colostral immunoglobulin concentrations in Holstein and Guernsey cows. Am. J. Vet. Res. 60:1136-1139.

Van Eetvelde, M., and G. Opsomer. 2020. Prenatal programming of later performance in dairy cattle. Vlaams Diergeneeskd. Tijdschr. 89. https://doi.org/10.21825/vdt.v89i1.15985.

von Konigslow, T. E., D. L. Renaud, T. F. Duffield, C. B. Winder, and D. F. Kelton. 2020. Assessing the utility of leukocyte differential cell counts for predicting morbidity, mortality, and growth in a grain-fed veal facility: A prospective single cohort study. J. Dairy Sci. 103:9332-9344. https://doi.org/10.3168/jds.2020-18532.

Winder, C. B., D. F. Kelton, and T. F. Duffield. 2016. Mortality risk factors for calves entering a multi-location white veal farm in Ontario, Canada. J. Dairy Sci. 99:10174-10181. https://doi.org/10 .3168/jds.2016-11345.

Yang, M., Y. Zou, Z. Wu, S. Li, and Z. Cao. 2015. Colostrum quality affects immune system establishment and intestinal development of neonatal calves. J. Dairy Sci. 98:7153-7163. https://doi.org/10 $.3168 /$ jds.2014-9238.

\section{ORCIDS}

F. Marcato $\odot$ https://orcid.org/0000-0002-7063-5955

H. van den Brand $\odot$ https://orcid.org/0000-0003-0477-169X

B. Kemp () https://orcid.org/0000-0002-9765-9105

B. Engel (ㄴ) https://orcid.org/0000-0002-7680-326X

S. K. Schnabel $\odot$ https://orcid.org/0000-0003-2338-3019

A. P. Koets (ㄴ) https://orcid.org/0000-0001-9809-3679

M. Wolthuis-Fillerup (1) https://orcid.org/0000-0001-9226-0368

K. van Reenen ๑ https://orcid.org/0000-0003-0356-9350 